Guidelines to Design Tangible Tabletop Activities for Children with Attention Deficit Hyperactivity Disorder

Eva Cerezo, Teresa Coma, Ana Cristina Blasco, Clara Bonillo, $\mathrm{M}^{\mathrm{a}}$ Ángeles Garrido, Sandra Baldassarri

PII:

DOI: S1071-5819(19)30001-1

Reference: https://doi.org/10.1016/j.ijhcs.2019.01.002 YIJHC 2284

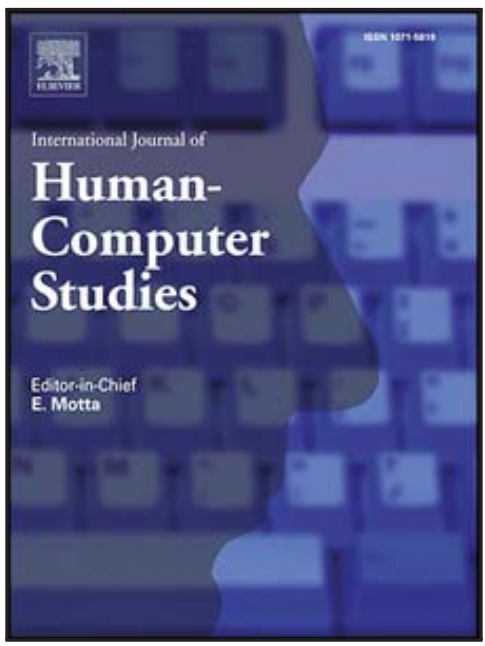

To appear in: International Journal of Human-Computer Studies

Received date: 22 December 2017

Revised date: $\quad 21$ November 2018

Accepted date: $\quad 9$ January 2019

Please cite this article as: Eva Cerezo, Teresa Coma, Ana Cristina Blasco, Clara Bonillo, $\mathrm{M}^{\mathrm{a}}$ Ángeles Garrido, Sandra Baldassarri , Guidelines to Design Tangible Tabletop Activities for Children with Attention Deficit Hyperactivity Disorder, International Journal of Human-Computer Studies (2019), doi: https://doi.org/10.1016/j.jhcs.2019.01.002

This is a PDF file of an unedited manuscript that has been accepted for publication. As a service to our customers we are providing this early version of the manuscript. The manuscript will undergo copyediting, typesetting, and review of the resulting proof before it is published in its final form. Please note that during the production process errors may be discovered which could affect the content, and all legal disclaimers that apply to the journal pertain. 


\section{Highlights}

- ADHD is one of the most frequent neurodevelopment disorders among children.

- There is a lack of works focusing on the design of applications for ADHD children.

- Tangible Tabletops have been used with children with diverse learning difficulties

- Tangible Tabletops have not been used with children with ADHD.

- Evaluation sessions with educators and children have been carried out.

- A deep study of the characteristics of ADHD children has also been carried out.

- A set of guidelines to design tabletop activities for ADHD children are proposed.

- They are quite are general and applicable to other areas.

- These guidelines could also be useful for other neurodiverse children.

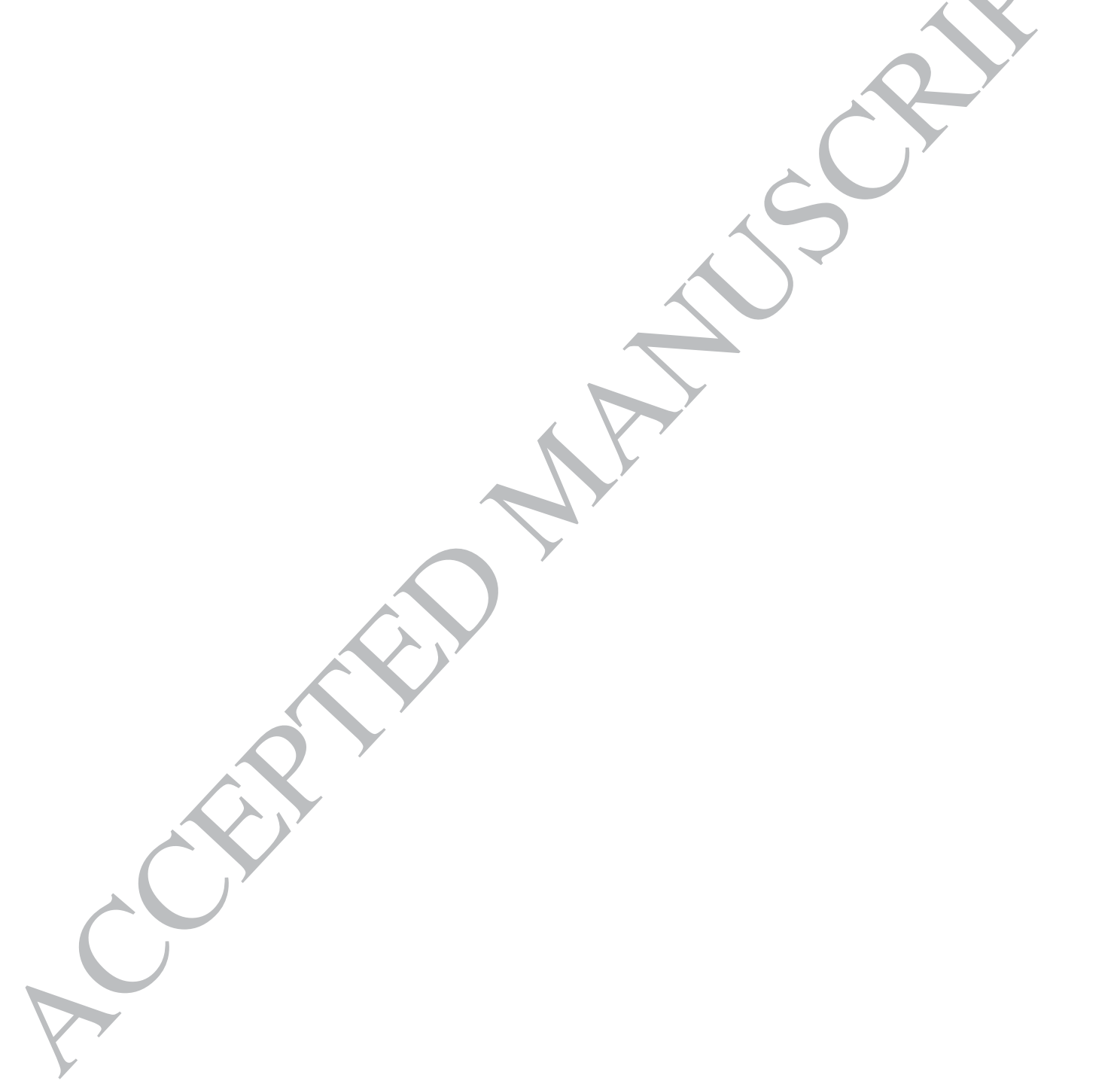




\title{
Guidelines to Design Tangible Tabletop Activities for Children with Attention Deficit Hyperactivity Disorder
}

\author{
AUTHORS \\ Eva Cerezo \\ Computer Science Department, Engineering Research Institute of Aragon (I3A), Universidad de Zaragoza, Ed. \\ Ada Byron, C/María de Luna n. 1, 50015 Zaragoza, Spain. \\ e-mail: ecerezo@unizar.es \\ Tel.: (+34) 976762356, Fax: (+34) 976761914
}

Teresa Coma

Psychology and Sociology Department, Universidad de Zaragoza, C/Pedro Cerbuna 12, 50009 Zaragoza, Spain. email: tcoma@unizar.es

Tel.: (+34) 976761995, Fax: (+34) 976762003

\section{Ana Cristina Blasco}

Education Sciences Department, Universidad de Zaragoza, C/Pedro Cerbuna 12, 50009 Zaragoza, Spain. email: anablas@unizar.es

Tel.: (+34) 976761315, Fax: (+34) 976762071

\section{Clara Bonillo (Corresponding Author)}

Computer Science Department, Universidad de Zaragoza, Ed. Ada Byron, C/María de Luna 1, 50015 Zaragoza, Spain.

e-mail: clarabf@unizar.es

Tel.: (+34) 976761916, Fax: (+34) 976761914

\section{$\mathbf{M}^{\mathrm{a}}$ Ángeles Garrido}

Psychology and Sociology Department, Universidad de Zaragoza, C/Pedro Cerbuna 12, 50009, Zaragoza, Spain. e-mail: garridoa@unizar.es

Tel.: (+34) 976761995, Fax: (+34) 976762003

\section{Sandra Baldassarri}

Computer Science Department, Engineering Research Institute of Aragon (I3A), Universidad de Zaragoza, Ed. Ada Byron, C/María de Luna. 1, 50015 Zaragoza, Spain.

e-mail: sandra@unizar.es

Tel.: (+34) 976762357, Fax: (+34) 976761914

\footnotetext{
Abstract

Attention deficit hyperactivity disorder is one of the most frequent neurodevelopmental disorders among children. In spite of this, there is a lack of HCI research specifically devoted to these children. This paper describes efforts to transfer previous experience with other neurodiverse children in the field of tangible tabletops to ADHD children. The results of evaluation sessions carried out in conjunction with an ADHD association, complemented with an in-depth study of their special characteristics and needs, have led to a set of guidelines oriented to the design of tangible tabletop activities. These guidelines are mostly general and applicable to the design of any interactive application oriented to ADHD children. They are also appropriate for applications for other neurodiverse children or, in fact, any child from a more inclusive perspective.
} 
Keywords: Tangible Interaction, Tabletop, ADHD, Children, Design.

\section{Declarations of interest: none}

\section{INTRODUCTION}

Attention deficit hyperactivity disorder (ADHD) is a mental disorder whose symptoms include attention and concentration difficulties, lack of emotional self-regulation, and a high level of impulsivity (Barkley, 2006; Bauermeister et al., 2005). It is one of the most frequent neurodevelopmental disorders among children, having a prevalence of around 5\% in Spain (Graham et al., 2011) and around 10\% in the USA (Akinbami et al, 2011). There are usually three kinds of interventions for ADHD children: psycho-pedagogical intervention, pharmacological intervention, and a combination of both (Sibley, 2014).

This paper focuses on psycho-pedagogical intervention, as a way to improve executive functions in ADHD children. Children with poor attention skills, in general, respond to a greater number of impulses, whether they are relevant or not to perform the tasks, and do not seem able to concentrate during the time necessary to perform them (Tripathi and Hasan, 2014). This can lead to an increase in the level of activity, which translates into disruptive attitudes that hinder learning and also its acceptance by teachers and peers. Another feature that is attributed to children with attention problems is their disorganization and impulsiveness, which leads them to have problems in making decisions and solving problems (Bauermeister at al, 2012). The problems of these children with attention, disorganization and impulsivity raise the consideration of the planning process as fundamental (Naglieri and Das, 2006). This is why during the intervention children should be guided to be able to improve planning, to regulate themselves to develop strategies to succeed, to improve their decisions and to pay attention to how they carry out their tasks. In this context, mediation becomes a key factor. Mediation is understood as the interaction between the educator and the child in order to guide him/her during the performance of the task. Dialogue helps to understand problems, to make inférences and comparisons, to elaborate hypotheses, to deduce rules and generalizations and, ultimately, it promotes abstract thinking (Feuerstein et al., 1980). Following an appropriate mediation procedure, traditional board games, like Chess, Pictionary, Scrabble, Monopoly, or simple puzzles, can be used to favor cognitive and relational processes. Mediation may take place among equals or through technological resources.

In fact, interactive computer tools and games may also be used in this kind of intervention. Interactive games are stimuli that can help to improve the attention and planning skills and may perform mediation functions encouraging children to explore, generate questions, and reflect. The use of video games and digital devices is not new in cognitive stimulation (Gunter, 1998; Granic et al., 2014). In particular, tabletop devices have become quite popular in recent years for improving different cognitive skills, especially for children with disabilities (Piper et al., 2006; Zarin and Fallman, 2011; Villafuerte et al., 2012). A tabletop is a computer device whose physical appearance is very similar to a standard table. Its surface is virtually augmented by using projections of images and sounds coming from a computer application, and the interaction is carried out through movements of the fingers on the tabletop surface (multi-touch) (Goh et al., 2012). This manner of interaction has several advantages since the wide surface of the tabletop provides a broad space to work visual and motor skills, the audio-visual stimulation motivates the user, and the tabletop allows working with a bigger range of activities that cover one or more aspects of cognitive stimulation. Nevertheless, multi-touch interaction has some drawbacks for small children (Mansor et al., 2008). For example, if the child's fingers are too small the system may have difficulty in correctly detecting them, which may complicate the performance of certain actions such as pointing to a virtual object or dragging it across the surface. In these cases, Tangible User Interfaces (TUI) represent a natural interaction alternative where the interaction between the user and the application should be done by using physical objects of quotidian use (Ishii and Ullmer, 1997). A tangible tabletop device can identify different objects placed on its surface, track the different user manipulations, and also show information related to such 
manipulations on the surface. By keeping physical objects on the physical side of the users, the emotional impact of the game is reinforced (Iwata et al., 2010) and important additional benefits emerge when applied to young children (Read and Markopulous, 2013) and to children with special needs (Li et al., 2008; Hendrix et al., 2009, Alessandrini et al., 2014). In fact, several comparison studies between tactile and tangible activities have been carried out showing that most children in the studies preferred tangible activities over tactile ones (Suárez et al, 2011). This preference is related to high levels of stimulation and enjoyment, derived from three TUI properties: physical interaction, rich feedback, and high levels of realism (Zuckerman et Gaz-Ol, 2013). Besides, tangible interfaces enabled more efficient and effective motor strategies (Antle and Wang, 2013), and were found to be more user friendly (Arnaud et al, 2016).

NIKVision (Marco et al., 2013), a vision-based tangible tabletop device for very young children and children with special needs, has been designed by our AffectiveLab group at the University of Zaragoza. With this tabletop, interactions are carried out by positioning objects on the tabletop surface, so children can play with the computer by manipulating conventional toys. NIKVision has been tested in nurseries, schools, and special education schools, and has proved useful when working with different kinds of learning difficulties (Marco et al., 2013b; Cerezo et al., 2015).

Through a national research project (Juguemos), we contacted an association of ADHD families and professionals. Having worked for so long with psychologists and pedagogues who are used to managing neurodiverse children (Dalton, 2013), the question that arose was the following: Would tangible tabletops also be useful for ADHD children? Considering the characteristics of tangible tabletops, mainly physical manipulation and collocated gaming, in addition to their strong motivational capability, our hypothesis was that they would be helpful devices to support the therapeutic work done on the common deficits and challenges associated to ADHD children. It seemed quite a reasonable hypothesis. Nevertheless, when we searched the literature for studies about tangible interaction and ADHD, the number of them was very limited and almost no specific ADHD design guidelines were found.

So, starting from our hypothesis (the usefulness of tangible tabletops in the ADHD context), we decided to carry out a preliminary study to assess the usability and potential of tangible tabletop activities with ADHD children and their educators. In parallel, an in-depth study of the specific characteristics of ADHD that should be taken into account when designing activities for such children was also done. As a result, we have come up with a set of guidelines to design applications for ADHD children. Some of them are specific to tangible interaction, but most of them are quite general and applicable to different kinds of games and interactive applications for other neurodiverse children.

The remainder of this paper is structured as follows. A review and analysis of related work is presented in Section 2. Section 3 describes the preliminary study carried out to assess the usability and potential of previously designed tangible tabletop activities for ADHD children. A study of the learning difficulties and cognitive deficits of ADHD as well as the applicable mediation models is presented in detail in section 4. Section 5 presents the resulting set of guidelines for the design of tangible activities focused on children with ADHD. Following these guidelines, two new tangible interactive activities were developed and evaluated, as explained in Section 6. Finally, Section 7 is devoted to conclusions and future work.

\section{STATE OF THE ART: SEARCHING FOR GUIDELINES}

In this section, a review of the literature relating to technological solutions used to work with children with ADHD is first presented. The few works that focus on guidelines to design applications for children with ADHD are subsequently reviewed.

\subsection{Technologies and applications for children with ADHD}


Several works relating to technologies specifically developed for children with ADHD can be found in the literature. The applications can be classified considering different contexts: desktop applications, augmented reality applications, and tangible interfaces.

In the context of desktop applications, ACTIVATETM (Activate, 2016) is a program that combines cognitive brain training with physical exercise. It is composed of several neuroscience-based games specifically designed to increase and strengthen the child's ability to concentrate and focus, to work memory, to acquire speed in information processing, cognitive flexibility, etc. 'Play Attention' (Play Attention, 2016) is a learning system to improve attention, behavior, and cognitive function for ADHD children and adults. It uses BodyWave technology to monitor attention cerebral signals. Both ACTIVATE and Play Attention have real time data modules that collect children's results and interactions, generating reports, alerts and statistics available for parents and educators. There are also websites such as ADDitude (ADDitude, 2016) that provide information and strategies to work with people with ADHD. The website also recommends, among other things, board games that can help such children work their abilities. Regarding the evaluation of the systems, the results shown on those websites indicate that the children who took part in these programs improved in some of their affected cognitive aspects.

In the context of augmented reality, Rizzo et al. (2000) developed a virtual classroom in order to work attention deficits. They make use of a head mounted display and different tracking devices to immerse children in the classroom. Children interact with the system through a virtual teacher, who assigns them different tasks to work the different types of attention (classified as focused, sustained, selective, alternating and divided) while several distracters are taking place. In order to prove the usability of the Virtual Classroom, the authors conducted a clinical trial to compare 8 children with ADHD (6-12 years of age) with 10 non-diagnosed male children. The trial consisted of showing the children a series of letters on the blackboard so that they could identify a specific sequence. The children had to ignore the distracters that occasionally appeared on the blackboard and focus on the sequence. After comparing the results, the authors concluded that the trial had good potential as a tool for conducting attention performance measurement, since it was able to clearly differentiate the two groups of children.

In the context of tangible interfaces, TangiPlan (Weisberg et al., 2014) is a system composed of six tangible objects whose objective is to help children work their executive functions. Each object represents a task that the child has to carry out in the morning. The child situates the objects at the places where the tasks have to be performed and selects the time to be devoted to every task. A preliminary evaluation was conducted with two children to gauge their response when using the prototype (Zuckerman et al., 2015). Firstly, the authors asked the children and their respective parents to complete a Likert questionnaire about their satisfaction with the children's morning routines, the children's background and the parents' involvement in the mentioned routines. Then, the authors lent the prototypes to both families for two weeks. After that time, the authors had another interview with both families to discuss their experience of using the prototypes. Some technical problems were found in the prototype, but both families approved of the non-intrusive aspect of the prototype and expressed their interest in using future versions of TangiPlan as it helped the children in their time management.

SitCap (Guía et al., 2015) is a system that allows children with ADHD to work their memory, attention and associative skills by playing three different games with three levels of difficulty. In order to interact with the system, children use cards with RFID tags integrated inside that they have to approach to a mobile device. Three evaluations were carried out at weekly intervals. The authors used a Smileyometer test, so that children could express their satisfaction when using the system, and a direct observation method. The results of the evaluations showed that the children enjoyed using the system and that their performance improved after having used the system several times. 
Finally, Garcia et al. (2013) make use of a Kinesiofeedback Toy that measures and assesses children's activity and provides them with feedback as to whether or not their behavior is within appropriate limits; they also propose the use of a wearable wrist device called WRISTWIT to support the learning process, suppressing undesired behavior in daily routines by means of positive feedback and rewards. Kinesiofeedback and WRISTWIT were tested in the field with children, proving that they were able to positively modify children's behavior during daily school routines.

As can be seen, most of these applications and systems help children with ADHD to work, basically, their cognitive skills (ACTIVATETM, Play Attention, ADDitude, Virtual Classroom, SitCap), while others focus on helping them in their daily routines (TangiPlan, Garcia et al., 2013). Surprisingly, social skills are generally not addressed, in spite of their importance for these children (Barkley, 2006). Also, most part of the works adopt observational or informal methods of evaluation to avoid disturb the children as much as possible while they are using the systems. Finally, although two works make use of tangible interfaces (Weisberg ét al., 2014; Guía et al., 2015) neither of them combines the Tangible Interaction paradigm with tabletops. Since this combination has proved to be highly motivating and offers several advantages when working with children with special needs, as mentioned in the introduction, our hypothesis is that it could also be useful when applied to children with ADHD.

\subsection{Designing for children with ADHD}

An exhaustive review of the literature relating to works that tackle the design of applications or games for children with ADHD revealed the following few works.

McKnight (McKnight, 2010) proposes fifteen guidelines to be followed by software designers in order to avoid excluding these children when developing new software. In fact, the author comments that, even if some of the guidelines are especially meaningful for children with ADHD, most of them are also valid for all kinds of users, not specifically for ADHD. The guidelines are quite general, without any particular software in mind, but clearly oriented to the design of educational materials and directly related with behavior management techniques. Seven of them are layout guidelines (see Table 1), including several that follow general design principles: the need for organizing the items of an application in an orderly way (MK4), the importance of using a large print and a clear font such as Arial when designing a system (MK6) or using calm and soothing colors instead of vivid ones (MK2). McKnight's other guidelines are environmental and interaction guidelines for supporting the mediation process. These include recommendations to always use positive feedback (MK3) or minimize distractions (MK11), which seem to be more focused on children with ADHD, and to allow ample rest periods and exercise breaks (MK10), to keep technology shut away unless it's being used (MK12), to keep a routine (MK13)and to maintain eye contact (MK15). As can be seen, some of them, specifically the recommendations to minimize distractions (MK11), to keep technology shut away unless it's being used (MK12) and to keep a routine (MK13), are focused on reducing external stimulation, keeping children away from natural environments. These types of guidelines originated in the sixties, from the first contributions of Cruickshank et al. (1961) where educative attention for ADHD children focused on the necessity of reducing external stimulation (including non-essential auditory and visual stimuli), of reducing the work space to a minimum, and of working with a very structured timetable. They also incorporate the behavioral perspective, stressing the importance of the educational material, of behavior modification techniques, of demarcating clear objectives and of breaking down complex tasks into subtasks. However, in the same period, Rost (1967) and Hallahan and Kaufman (1976) found no relation between reduced and structured environmental and academic achievement.

Pykhtina et al. (2012) propose design guidelines in the context of non-directive play therapy with children. They are the authors of Magic Land, a package of activities intended to be played on an interactive multi-touch tabletop that were not specifically designed for using with children suffering cognitive limitations. After observing two children diagnosed with ADHD playing the games, they speculated on design guidelines for systems that aim to 
support children experiencing problems with memory, concentration and attention in play therapy. They recommend the design of simple games that enable the expression of feelings and creativity in a way that does not require much time commitment, concentration or complex cognitive abilities (P1), using calming music and a highly responsive and sturdy enough device so that the child does not get frustrated. In spite of being in the context of non-directive play (with no adult intervention), they realize the necessity of giving enough structure and context instructions to guide and support the child (P2). They do not recommend the addition of prompts or other attention catching options (P3). They conclude with the recommendation of providing the child with diverse options (e.g. through combining tangible toys and digital environment on an interactive tabletop) to avoid the child getting bored quickly and to improve motivation (P4).

Sonne et al. (2016) present a design framework in the context of developing assistive technology for ADHD children and their families. The framework is based on four design strategies: to provide structure to facilitate activities (S1), to minimize distractions (S2), to encourage praise and rewards (S3) and to integrate and report standardized ADHD measures (S4). Although arising from assistive technology, they could be applied in a more general context, and some of them are clearly aligned with the other two works.

In Table 1, the fifteen guidelines extracted by McKnight (MK1-MK15), the four extracted by Pykhtina et al. (P1P4) and the four extracted by Sonne et al. (S1-S4) have been classified in three relevant groups: Layout Guidelines, covering those related with the way the information is presented, Mediation and Environment Guidelines, including those related with the environment and interaction in the learning process, and Other Guidelines.

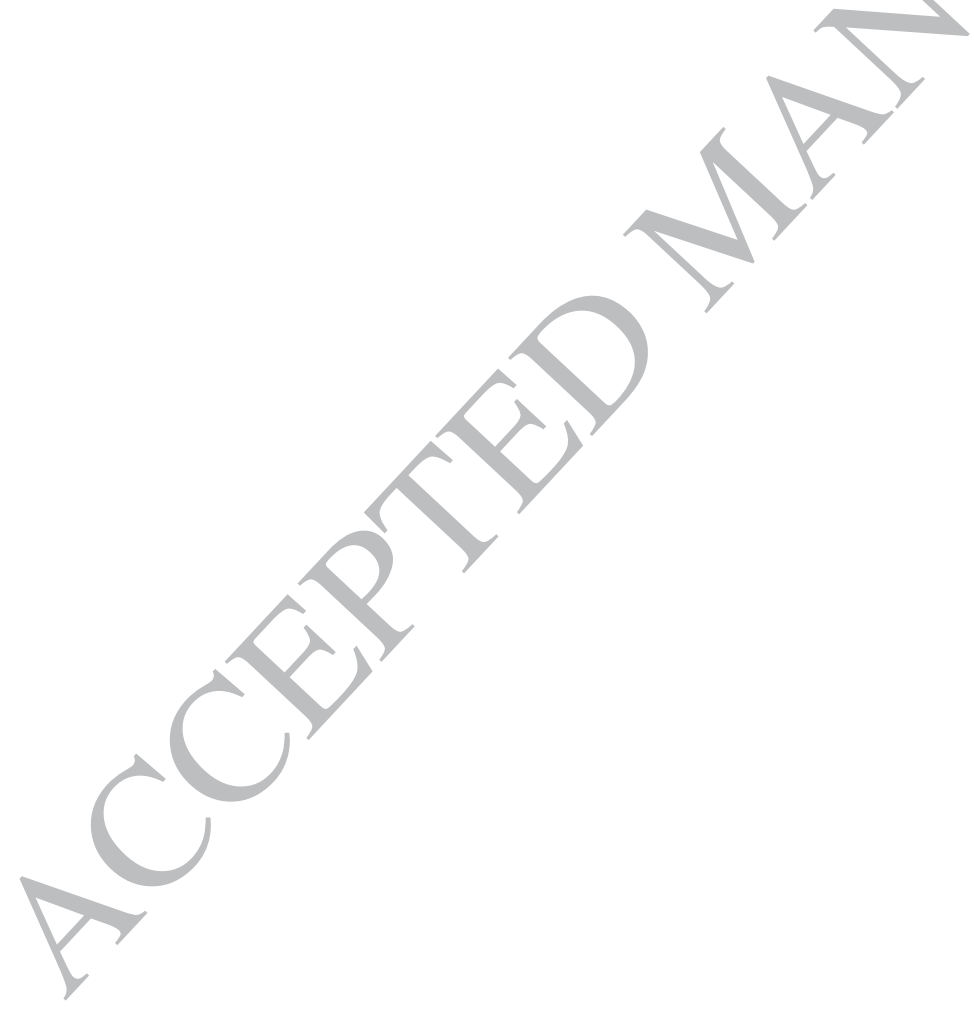


Table 1. Guidelines found in the literature to design applications for children with ADHD.

\begin{tabular}{|c|}
\hline Layout Guidelines \\
\hline MK1. Design materials so the layout is neat and uncluttered \\
\hline MK2. Provide a 'calm' environment, with soothing colors \\
\hline MK4. Organize items in an orderly way \\
\hline MK5. Distinguish important information by putting it in bold o \\
\hline MK6. Use large print and a clear sans-serif font \\
\hline MK7. Help pupils follow text by writing/highlighting alternate lines in different colors \\
\hline MK8. If the pupil needs to work through a series of questions, help them keep their place $b$ \\
\hline Mediation and Environment Guidelines \\
\hline MK3. Provide a high-reinforcement environment / S3. Encourage praise and rewards \\
\hline $\begin{array}{l}\text { MK14. Minimize surprises / S2. Minimize distractions / P3. Do not recommend the addition of prompts or } \\
\text { other attention catching options. }\end{array}$ \\
\hline $\begin{array}{l}\text { P2. Give enough structure and context instructions to guide and support the child / S1. Provide structure to } \\
\text { facilitate activities }\end{array}$ \\
\hline MK9. Use brief and clear instructions \\
\hline MK10. Allow ample rest periods and exercise breaks \\
\hline MK11. Have a workstation that is enclosed, in a soundproof environment, with few distractions around \\
\hline MK12. Keep technology shut away unless it's being used \\
\hline MK13. Keep a routine, e.g. don't change teachers \\
\hline MK15. Maintain eye contact \\
\hline Other Guidelines \\
\hline $\begin{array}{l}\text { P1. Design simple games that enable the expression of feelings and creativity in a way that does not require } \\
\text { much time commitment, concentration or eomplex cognitive abilities }\end{array}$ \\
\hline $\begin{array}{l}\text { P4 Provide the child with diverse options (e.g. through combining tangible toys and digital environment on } \\
\text { an interactive tabletop) to avoid the child getting bored quickly and to improve motivation }\end{array}$ \\
\hline
\end{tabular}

The first group is made up of seven Layout Guidelines focused on the organization and visual aspects of the interfaces. Most of them are aligned with general design principles for obtaining good and usable systems. In fact, in order to design and develop applications oriented to ADHD children, the basic rules for usability and interface design must be considered, as in other interfaces or applications. Therefore, the ten principles of interaction design established by Nielsen (1994) to improve the system's usability, the Eight Golden Rules of Shneiderman (2010) to design better interfaces, and the 7 Universal Design principles (Story et al., 1998) to develop interfaces that can be used by as many people as possible, should be taken into account.

The second group comprises nine mediation and environment guidelines oriented to the generation of efficient interactions (either technological or personal) in the learning process. These are especially related with the special characteristics of ADHD children. The first three guidelines (shaded in pink) are common to two or all three works. The other six guidelines are also focused on favoring efficient mediation and interaction with the environment; some of them are aimed at technology (MK11 Have a workstation that is enclosed, or MK12 Keep technology shut away unless it's being used), some must be taken into account by the educator (MK15 Maintain eye contact) while others can be taken into consideration either by the technology and/or the educator. 
Finally, the last group (Other Guidelines) includes guidelines that are quite dependent on the type of application to be designed: assistive technology (S4 Integrate and report standardized ADHD measures) or effective nondirected play (P1 Design simple games that enable the expression of feelings and creativity, P4 Provide the child with diverse options). Guideline P4 explicitly recommends the combination of tangible toys and a digital environment on an interactive tabletop. However, as seen in the previous section, no work addressing tangible tabletops and ADHD can be found in the literature. This is why we decided to get direct feedback from ADHD children interacting with our tangible tabletop, as explained in the next section.

\section{TANGIBLE TABLETOP ACTIVITIES AND ADHD CHILDREN: PRELIMINARY STUDY}

In this section we focus on studying the potential of using tangible tabletops with ADHD children. First, a review of the advantages of tangible interfaces to foster learning is provided. Second, a brief description of the tangible tabletop NikVision is given. An initial study carried out with ADHD children is then explained. Finally, the results and conclusions obtained from this first experience are presented.

\subsection{Tangible tabletops as learning tools}

Tangible tabletops are an example of physical interfaces demonstrated to lead to more engaging and embodied experiences (Zuckerman and Gal-Oz, 2013). Embodiment has a long and complex history, with continued debate from various disciplinary perspectives, including cognition and Human-Computer Interaction (HCI) (Farr et al., 2012). Embodied cognition emphasizes how the particulars of human bodies acting in complex physical, social, and cultural environments determine perceptual and cognitive structures, processes and operations.

A wealth of developmental psychology and media-studies literature provides evidence for the importance of understanding the role of action and the environment in the development of children's thinking skills. Piaget and Cook (1952) began a long tradition when they suggested that cognitive structuring through schemata accommodation and assimilation requires both physical and mental actions. More recently, Healy (1998) argued for the importance of physicality in childhood, in particular for children's cognitive development. Within HCI, Dourish's emphasis on cognition being embodied, rather than only situated in the brain, suggests the importance of using the body to create meaning when learning (Dourish, 2004). In more recent years, embodiment has become recognized as a key element in child computer interaction design (Antle, 2009). More specifically, in the learning domain, there is a consensus about the advantages of tangible interfaces as teaching tools due to their following characteristics (Price and Marshall, 2013):

- Sensory engagement - the natural way children learn, engaging multiple senses (in this case touch, vision, auditory) in a constructive process.

- Accessibility - dramatically improves accessibility to younger children, to people with learning disabilities, and to novices.

- Group learning - provides a multi-hand interface, does not give the control to one person, facilitates natural group interaction, and promotes group discussion.

These advantages have been proved for teaching abstract concepts (Zuckermann et al., 2005), in programming learning environments (Horn et al., 2012), and also with students with special educational needs (SEN) (Lechelt el al., 2018). In fact, TUIs have been claimed as especially suitable for SEN children (Falcão et Price, 2010). Moreover, the possibility of sharing physical artifacts within an open and flexible environment invites collective interaction, providing a safety net that encourages social interaction (Farr et al., 2010). In their study with Asperger Syndrome students, Piper et al (2006) also saw the benefits inherent in the use of tabletop technology such as the support given to social interaction and providing a shared experience for learners and educators, both of which are central to the learning process (Vygotsky, 1996). The present authors have also collected very positive experiences when working with their NIKVision tangible tabletop and SEN children in recent years 
(Cerezo et al., 2015; Bonillo et al., 2016). The next subsection describes the NIKVision tabletop used in these experiences.

\subsection{NIKVision tabletop}

As indicated in the introduction, tangible interaction and, specifically, tangible tabletops have been successfully used in educative and therapeutic contexts as technological alternatives to other kinds of more conventional devices. The NIKVision tabletop (Marco et al., 2013) uses well-known techniques for multi-touch active surfaces (Schöning et al., 2010), but its design is mainly focused on tangible interaction and therefore on the handling of physical objects on the table surface. It is easily mountable and dismountable and, because it was initially oriented to kindergarten children, it is robust and safe (NIKVision)

Children use NIKVision by manipulating conventional toys on the surface (Fig.1a). A USB video camera is placed inside the table, capturing the surface from below (Fig.1b). Visual recognition software runs in a computer station (Fig.1c) which also handles the game software and the tabletop active image provided by a video projector under the table (Fig.1d) through a mirror inside the table (Fig.1e). The image output can also be shown on a conventional computer monitor (Fig.1f) adjacent to the table. Visual recognition and tracking of objects manipulated on the table is provided by the reacTIVision framework (Kaltenbrunner and Bencina, 2007). A printed marker attached to the base gives each toy a digital identification.

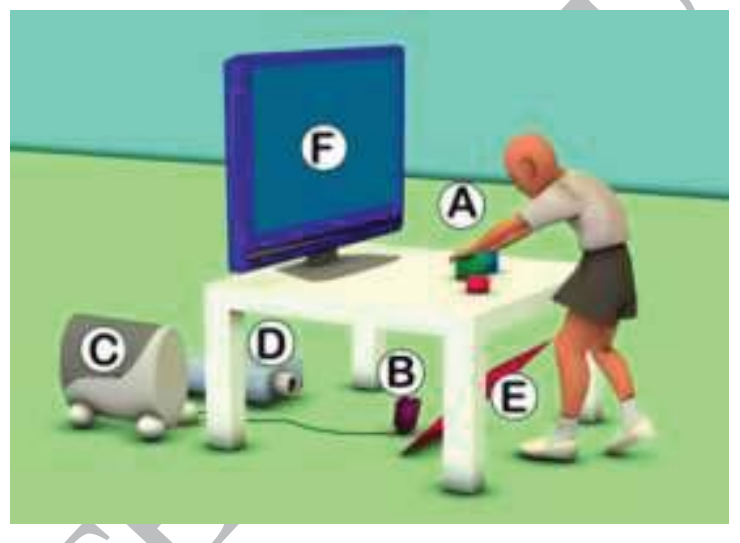

Fig. 1. NIKVision tabletop components.

The activities are shown on the tabletop and the user can play by placing different physical objects on the surface, as can be seen in Fig 2. During play, children move the toys over the translucent surface of the table, putting the base of the toys in contact with the table to enable the camera to see the markers located under the base. The manipulations that visual recognition software is able to track are movements over the surface. Children can grab the toys, drag them and rotate them over the surface and, so long as the base with the marker remains on the table, the software can track their orientation. 


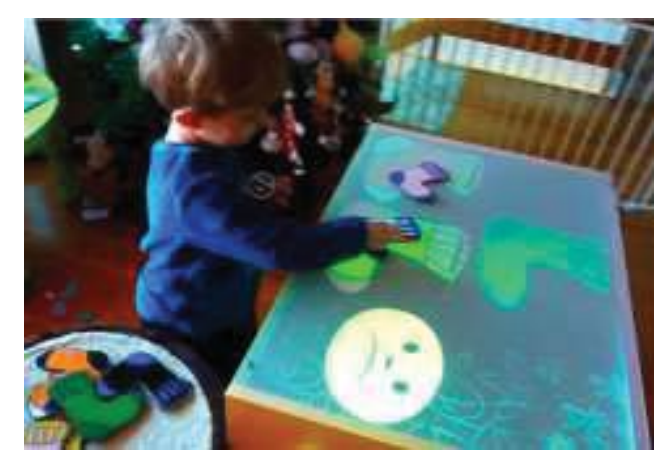

Fig. 2. Children playing on the NIKVision tabletop

\subsection{Preliminary study: Methodology}

It was decided to make a preliminary study to assess the usability and potential of our tangible tabletop activities with ADHD children. To do so, we contacted Atenciona, an association of ADHD families and professionals. In the study, Atenciona children took part as well as their educators, as their opinions about the potential of the tangible tabletop and its activities for psycho-pedagogical intervention were one of the aims of the study.

In a previous exercise, the authors had collaborated with one of the centers of the Aragonese Institute of Social Services and developed specific activities for their children with developmental delays. The activities were designed considering the most common problems of the children attending the center (general motor and cognitive delays and social problems) and also the age of the children (2-5 years). A user-centered-design methodology was used in which the children and their therapists took part in all the development process (Bonillo et al., 2017).

In a first meeting at the Atenciona center the activities were shown to the educators. Although they had been developed for children whose characteristics and age range did not directly correspond to the Atenciona ADHD children, the educators thought they could be used and they selected ten of them. In Table 2 the selected activities are shown indicating the name, a brief description of the activity, the image projected on the tabletop surface and the physical toys necessary to play. They are grouped according to the skill they were designed to work: visual attention, memory and planning.

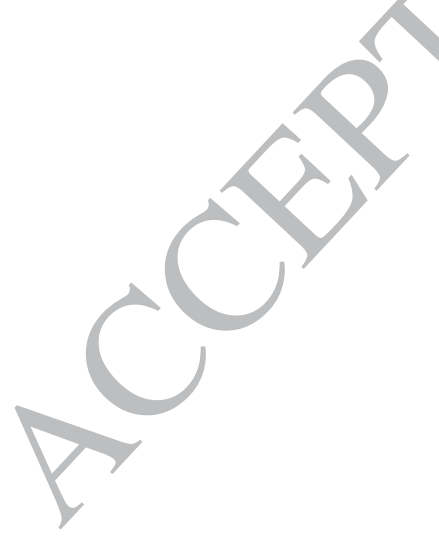


Table 2. Tabletop activities used in the evaluations

\begin{tabular}{|c|c|c|}
\hline & Description of the activity & Tabletop Image and Physical Toys \\
\hline \multirow{4}{*}{$\begin{array}{c}\mathbf{A} \\
\mathbf{T} \\
\mathbf{T} \\
\mathbf{E} \\
\mathbf{N} \\
\mathbf{T} \\
\mathbf{I} \\
\mathbf{O} \\
\mathbf{N}\end{array}$} & $\begin{array}{l}\text { Bees: the tabletop surface shows an animation of a } \\
\text { tree full of hives with several bees flying around. } \\
\text { Among the bees, there is only one that carries honey. } \\
\text { The activity is completed when the child places a } \\
\text { honey pot toy under the hive where the bee with honey } \\
\text { disappeared. }\end{array}$ & \\
\hline & $\begin{array}{l}\text { Fishing: the tabletop surface shows an animation of a } \\
\text { pond with a cat and with shapes of the fishes that the } \\
\text { cat likes. To complete the activity, the child has to use } \\
\text { one of the rods to catch the fish that have the same } \\
\text { shape and color as the ones next to the cat and place } \\
\text { them on the pier. }\end{array}$ & \\
\hline & $\begin{array}{l}\text { Plumber: the tabletop surface shows an animation of } \\
\text { a pipe that has water leaks of different colors. To } \\
\text { complete the activity, the children have to place their } \\
\text { gloved hands over the segments of the pipe that have } \\
\text { water leaks of the same color as the gloves they are } \\
\text { wearing. }\end{array}$ & \\
\hline & $\begin{array}{l}\text { Twister: this activity is a tabletop version of the } \\
\text { original Twister game. The surface of the tabletop } \\
\text { shows a twister roulette and four rectangular areas of } \\
\text { different colors where the child has to place his hands. }\end{array}$ & 1 \\
\hline \multirow{2}{*}{$\begin{array}{l}\mathbf{M} \\
\mathbf{E} \\
\mathbf{M} \\
\mathbf{O} \\
\mathbf{R} \\
\mathbf{Y}\end{array}$} & $\begin{array}{l}\text { Kraken: the tabletop surface shows the image of a } \\
\text { sea with krakens in some of the squares. After five } \\
\text { seconds the image disappears and only the sea is } \\
\text { shown. To complete de activity the child has to move } \\
\text { the boat to reach the treasure, avoiding the squares on } \\
\text { which there was a kraken. }\end{array}$ & 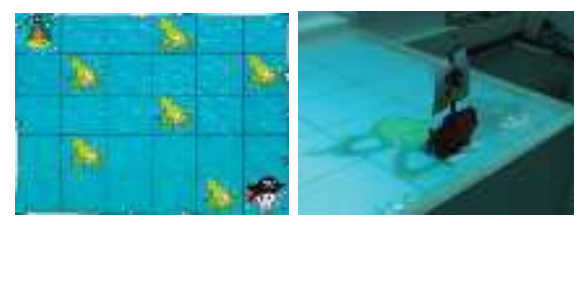 \\
\hline & $\begin{array}{l}\text { Shopping List: the surface shows an image with a } \\
\text { list of several foodstuffs for five seconds. The image } \\
\text { of the list is then replaced by an image of a shopping } \\
\text { bag. The child has to remember the content of the list } \\
\text { and select the correct foodstuffs to place them in the } \\
\text { bag. }\end{array}$ & 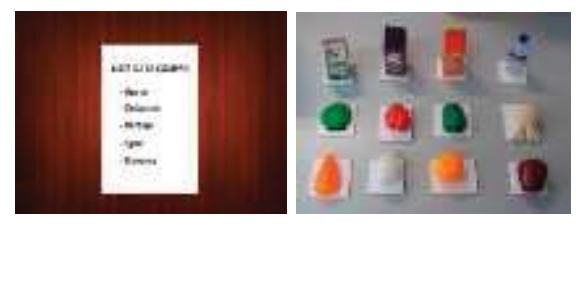 \\
\hline $\begin{array}{l}\mathbf{P} \\
\mathbf{L}\end{array}$ & $\begin{array}{l}\text { Analogies: the child has a set of pieces. Each piece is } \\
\text { composed of two pictograms and each pictogram can } \\
\text { be paired with another pictogram from a different } \\
\text { piece. The goal of the activity is to compose a chain by } \\
\text { pairing the physical objects with the correct } \\
\text { pictograms. }\end{array}$ & 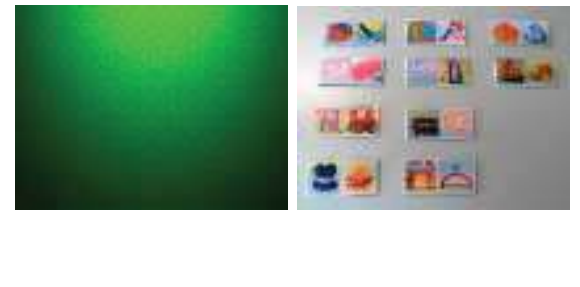 \\
\hline
\end{tabular}




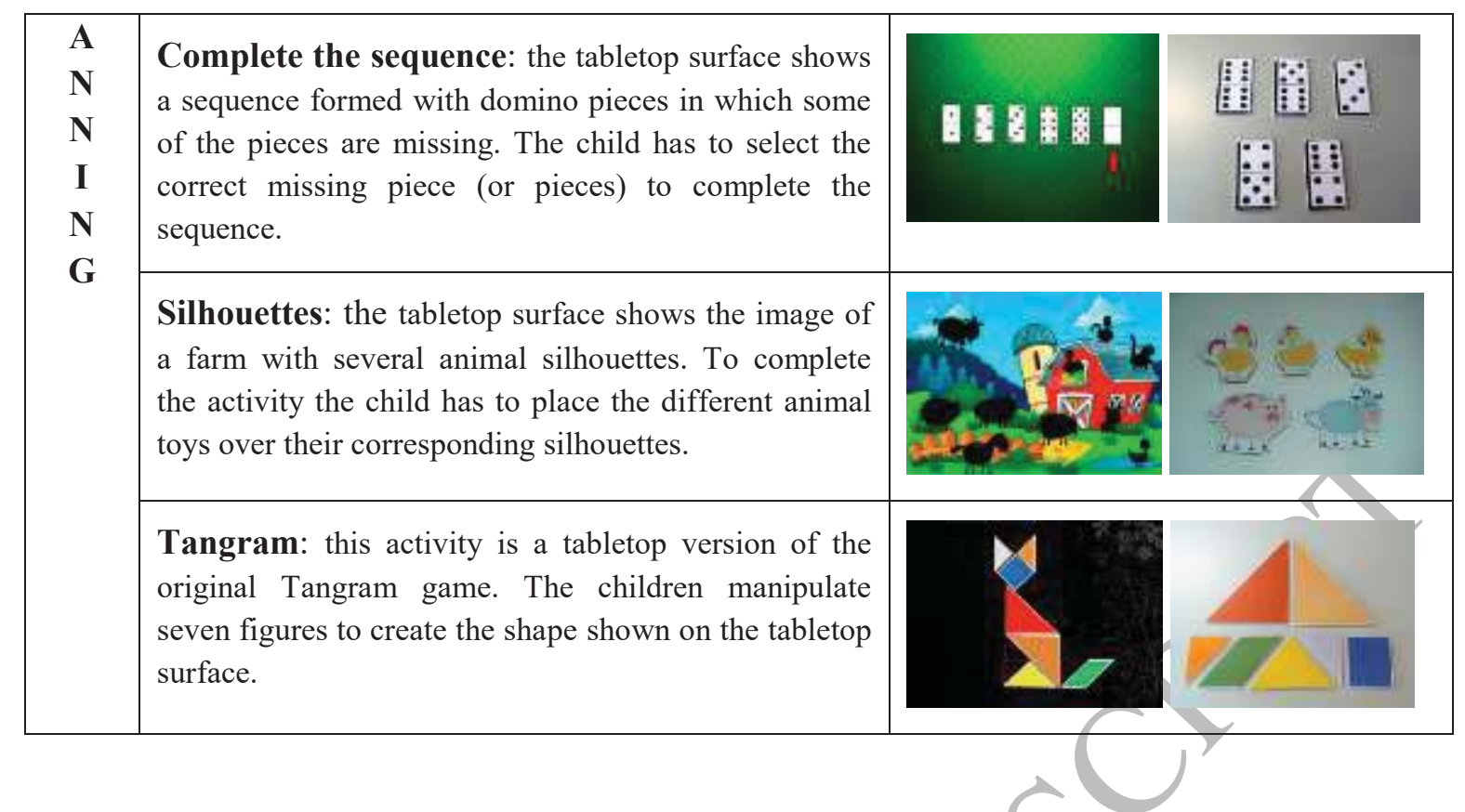

In order to carry out this preliminary session, a NIKVision tabletop was installed in the Atenciona center, in one of the rooms that the educators used for their therapies and exercises. The children who tested the activities were receiving psycho-pedagogical intervention in the center. A total of 26 children participated in the sessions (24 boys and 2 girls), the youngest being 6 years old and the oldest 14 years old. Most of them were diagnosed with either ADHD or ADD (Attention Deficit Disorder), all had learning difficulties (which is why they attended the center) and many had behavior problems (see their characteristics in Table 3). The evaluations were carried out during three days and each session lasted around 20 minutes. Every child tested a minimum of three activities chosen by the educator according to the child's capacities and the skills that they wanted to work with (memory, attention or planning).

Table 3. Characteristics of the children taking part in the evaluations

\begin{tabular}{|c|l|}
\hline Number of children & Characteristics \\
\hline 9 & Mild ADHD \\
\hline 9 & Moderate ADHD, impulsive, behavior problems \\
\hline 3 & Mild ADD \\
\hline 3 & Moderate ADD \\
\hline 1 & Moderate Asperger \\
\hline 1 & Mild intellectual disability \\
\hline
\end{tabular}

The educators, a NIKVision expert and a psychologist were present in all the sessions. The method of evaluation was participant observation (Cohen et al., 2007), consisting of taking notes during the sessions about the children's behavior and reactions (Kawulich, 2005) since video recording was not allowed. The educators were responsible for observing the children's behavior while playing so that the activities could be stopped or changed if the educator considered that a child was getting tired or too distracted. The NIKVision expert controlled the 
tabletop and provided the children with the toys for the activities. Finally, the psychologist took notes about the children's particular behavior: if the game was unable to hold their attention, if they did not understand how to continue playing at some point of the game, or if they did not recognize some of the objects.

The activities were tested individually and in groups. First, the children played alone with the activities that could not be adapted to more than one person (Bees, Kraken, and Shopping List), and then they played in groups with the rest of the activities. The Twister and Plumber activities had been specifically designed for groups. However, some of the activities tested in groups, such as Analogies and Sequences, had been designed to be played individually. In these cases, the activities were played in groups by naming one of the children as the group representative, by dividing the children in subgroups, or by taking turns when giving the answer to the activity.

\subsection{Preliminary study: Results and first recommendations}

Based on the observations carried out by the evaluators, the following conclusions could be extracted.

The activities and interactions seem to be quite usable for ADHD children: they played with the NIKVision tabletop without any difficulties, individually and in groups. The children showed their satisfaction when playing with it and all of them could complete the activities. Their educators expressed the potentialities of the tabletop: "it awakens interest and increases motivation and that means that the attention is maintained for more time focused on solving problems", "it gets more interaction between children", "children enjoyed the joint resolution, learning from each other".

However, when analyzing the observations, it was realized that some aspects of the activities had to be improved in order to create new activities specifically aimed at children with ADHD: there were several common mistakes made by children regardless of their age and the level of difficulty of the activity. These problems had not been detected in the previous evaluations of the activities with children with developmental delays. The analysis of the observed problems allowed us to obtain some initial recommendations to design activities for these children. The main problems detected and the recommendations $(\mathrm{R})$ to avoid them are presented below.

\section{Problems to initially understand the activities.}

On several occasions, the children did not pay attention to the audio instructions given by the tabletop and consequently they did not understand what they had to do. As a result, the educators had to go back to the main menu and restart the activity, telling the children to pay attention to the audio instructions. On other occasions, they heard the instructions but these were not sufficiently clear.

\section{R1. Instructions have to be clear and offer the possibility of being replayed. \\ Problems to identify some toys.}

The children sometimes had problems to identify the toys they had to use, either because the shape of the toy was not clear (for example, in 'Shopping List' the onion toy was mistaken several times) or because the children did not know the object (in 'Analogies' the children did not recognize some of the pictures, for example the ball of yarn).

\section{R2. Objects have to be easily identifiable by the children.}

\section{Problems to be aware of the time.}

When there was a set time to do a specific task (for example, to memorize something), the activity did not have any kind of countdown and consequently several children let the time pass without doing what they had to do. 


\section{R3. When there is a limited time to complete a task, this has to be clearly indicated.}

\section{Problems to complete the activities.}

Sometimes the children understood what they had to do and what the objective of the game was, but they did not know how to act to achieve this. In such cases, the children often played through trial and error, simply putting the nearest object on the tabletop to obtain some kind of response or hint. When this happened, the educator wanted to begin again and repeat the task, but this was not possible as the whole game would have to have been restarted. Besides, when the children failed a specific task because they had not understood the activity correctly, they also wanted to repeat just that task, and not the whole game.

\section{R4. The educator should be able to control the whole game, including the possibility of repeating every task.}

\section{Problems to memorize some elements.}

The time to memorize the different elements in some of the games (food in 'Shopping List', position of the monsters in 'Kraken') was too short. In general, it was difficult for the children to memorize more than three elements.

\section{R5. Consider carefully the number of elements to memorize and the time to assimilate them. The time should} be established by the educator.

Problems playing in-group

It was observed that children usually became more distracted when playing in groups than individually. While the Twister and Plumber activities worked well when playing in groups, those adapted to be played by more than one child did not work so well, since they had not been designed for that purpose. In most cases, the children did not collaborate but just competed against each other to see who was the fastest to solve the exercise. Competiveness does not favor the control of the impulsivity, a problem for these children, whereas collaborative play may help them to learn self-regulation and respect for others' rhythms.

R6. The game should be designed to encourage children to interact, fostering joint resolution of problems and not competition.

Finally, despite the limitations revealed in the evaluation of these activities (which were not specifically aimed at children with ADHD), the positive comments from the educators encouraged us to go ahead. However, we realized that in order to develop activities for children with ADHD, a careful design of the activities must be followed. For that purpose, we thought it was essential to analyze in depth the characteristics of ADHD children, considering their shortcomings and potentials, the way they process information and the mediation role that technology and digital games (in this case, the tangible tabletop) should adopt. In the following section the studies carried out are presented in detail.

\section{STUDYING ADHD CHILDREN: LEARNING PROCESS AND MEDIATION}

The aim of this section is to establish a reference framework to guide the design of activities for ADHD children. We first present a study of the learning processes of ADHD children, based on the PASS model. In these learning processes, mediation is also essential. Therefore, we also analyze in detail the interactions between the child, the facilitator (educator), and the interactive game, delimiting the role of each and giving recommendations to achieve a good mediation process. In both subsections design recommendations are also given.

\subsection{The PASS model: Understanding ADHD children to foster their learning processes}


The PASS (Planning-Attention-Simultaneous-Successive, Naglieri and Das, 1988) model combines neurological, psychological, and educational aspects and helps to understand how children behave during their learning process. In this section, we analyze how this model can help understand the behavior of children with attention deficit, hyperactive or not, when they face learning tasks, and also what factors are necessary to consider in order to fulfill their educational needs.

There are three functional units in the PASS model: attention (first functional unit), codification (second functional unit) and planning (third functional unit). There are two types of codification: simultaneous and successive; and there are three types of attention: arousal, selective and sustained. All these units are closely interrelated. Codification and planning interact to execute several actions and to facilitate knowledge acquisition and, at the same time, both these functional units depend on the existence of an adequate alert state (attention) so that learning can take place.

In the PASS model all the components act in an interactive way but, depending on the characteristics and requirements of the task to be performed, the participation of each process varies. The tasks can be codified in different manners, and the way to treat the information and how to perform the task are both forms of planning. Also, the intervention of attention is essential, and this must be sufficiently high so that the plans of action can be generated and used.

In fact, among these processes, attention has an important relevance in children with ADHD. It is composed of two other processes: one of them is automatic, doesn't require any effort and isn't controlled (arousal); the other process is conscious, requires effort and is related to and depends not only on the attention functional unit but also on the planning functional unit. Arousal is related to being alert, and it can vary depending on external conditions (cold, heat, noise...) and internal conditions (affective, and cognitive). Attention has been considered as an essential construct in psychology (James, 1890) and during recent years it has been an important research area in the context of learning difficulties (Mahapatra, 2016; Taddei et al., 2011). These research studies have focused particularly on selective attention, which allows children to concentrate exclusively on the relevant stimuli, and sustained attention, which is related to the ability to maintain attention for a longer period of time. Technology may play a relevant role in both cases: a careful selection of different types of stimuli may help the child focus attention; and these stimuli may also improye motivation and engagement with the activity. In fact, in the case of tangible interaction, manipulative materials may be very attractive for children, adding a ludic component to the task. The task itself becomes a source of interest and motivation, activating the attentional process.

Children with poor attention skills are usually described as inattentive or as easily distracted. In general, they respond to a bigger number of stimuli, relevant or not, and are unable to concentrate during the performance of the task in hand. This results in an increase in their activity level which, in turn, can lead to a disruptive attitude at school. Consequently, these/children develop behaviors that not only hinder their learning but also negatively affect their acceptance by teachers and schoolmates. However, the relationship between learning difficulties and attention problems is complex. In this context, Lahey et al. (1978) differentiate between behavior problems, learning difficulties, personality problems and hyperactive behavior. From this point of view, children with hyperactive behavior may (or not) display learning difficulties (Mayes et al., 2000).

As previously seen, planning is closely related with attention. In the PASS model, planning requires cognition and behavior to be active and strategic, instead of passive. In cases where there is too much information, or there are different processing options, it is necessary to make decisions, and this requires active and strategic thinking. Planning is necessary for solving new problems or tasks. Developing the planning functional unit will aid in managing children's inappropriate level of arousal, will facilitate plans for strategic performance, and will allow their self-regulation (Barkley, 2006). Therefore, for children with poor attention skills, both the contents of the activities and the mediation and interaction processes that take place during the activities are essential. 
Another essential issue to take into account is the social component. If the child can work the reflection skill about their own learning processes through a social act, this allows him/her to take joint decisions, enriched with different contributions. Moreover, the individual perception of the environment can be improved by sharing experiences with others, since other people can provide different views and perspectives that modify the child's comprehension, influencing his or her decision-making process. For a successful joint action, the aims, knowledge and beliefs of all participants must be considered, sharing them and working in groups and not individually, in order to achieve a greater benefit. In this way, the group thinks only as one and the individual is capable of communicating the thoughts and reflections of the whole group to other people (Frith, 2012). Furthermore, the interaction and the joint action with colleagues improve problem solving when it is necessary to select data that provide specific knowledge. In this sense, it is essential to promote the interaction between children and the joint resolution of problems.

In conclusion, the PASS model explains how attention problems have consequences in all the processes involved in learning. In particular, attention can interfere in the planning process, which is responsible for the construction, execution and control of plans. Therefore, not only selective attention but also strategic behavior and metacognitive knowledge must be worked with these children, focusing on the planning process and promoting interaction. A technological device may have an important role in this process. In/particular, we have seen (section 3) that tangible interaction tabletops have several characteristics that make them potentially useful for the education of ADHD children: sensory engagement, accessibility and group learning. For a greater educative impact on the child, when designing activities it is necessary to:

- Focus specifically on selective attention and planning (R7).

- Design activities that bring cognitive challenges to the children, stimulating their attention and their development potential (R8).

- Develop activities that favor reflection on the consequences of their actions, considering alternatives and sharing their points of view with others (R9).

- Make the most of the manipulative possibilities of the tabletop as a resource to favor learning, interest, involvement and motivation of the children (R10).

\subsection{Recommendations for an effective mediation process through interactive games}

As we have seen, difficulties in attention processes affect other processes, especially those related to planning, so the internal construction of children's experience and their self-regulation are key aspects to consider. Through interaction, mediators generate opportunities to encourage abstract thinking by favoring news ways to perceive, challenge, and be open to other options and emphasize the process of change as a physical experience. Feuerstein et al. (1980) call this type of interaction "mediation" whenever it has a sense of change, what it is called "cognitive modifiability". This cognitive modifiability requires the mediator to work in Vygotsky's "Zone of Proximal Development”' (1996). In their work, Feuerstein et al. (1991) differentiate eleven categories or types of mediation (Table 4) that determine the kind of questions used to mediate in the learning process. 
Table 4. Feuerstein's mediation categories and aims

\begin{tabular}{|c|c|}
\hline Mediation category & Mediation aim \\
\hline Intentionality and reciprocity & $\begin{array}{l}\text { To find the meaning of the task and to be actively engaged in order to } \\
\text { promote active responses. }\end{array}$ \\
\hline Transcendence & To generate new needs (precision, accuracy, new knowledge...). \\
\hline Meaning & To encourage meaningful questioning. \\
\hline Feeling of competence & $\begin{array}{l}\text { To feel acknowledged, to acknowledge oneself, and to show it with positive } \\
\text { stimuli. }\end{array}$ \\
\hline Regulation and control of behavior & To find out a more formal way of sharing: explaining answers, strategies... \\
\hline Sharing behavior & $\begin{array}{l}\text { To help to analyze and to argue their own answers and to express their own } \\
\text { ideas. }\end{array}$ \\
\hline $\begin{array}{l}\text { Individual and physiological } \\
\text { differentiation }\end{array}$ & $\begin{array}{l}\text { To encourage convergent and divergent points of view and support their } \\
\text { answers while noticing how they differ from other styles. }\end{array}$ \\
\hline Planning & $\begin{array}{l}\text { To become more flexible by including new information and generating new } \\
\text { responses as a result. }\end{array}$ \\
\hline $\begin{array}{c}\text { Challenge: Search for novelty and } \\
\text { complexity }\end{array}$ & $\begin{array}{l}\text { To acquire flexibility, to include new perspectives and generate new } \\
\text { answers. }\end{array}$ \\
\hline Structural change & To facilitate a higher level of abstraction. \\
\hline Search for an optimistic alternative & $\begin{array}{l}\text { To anticipate the future using the situation in which the children have } \\
\text { achieved their objectives. This information facilitates their development. }\end{array}$ \\
\hline
\end{tabular}

Many studies have validated the potential of games for motivating learning and the improvement of academic performance (Bul et al., 2016; Erhel and Jamet, 2013; Haring et al., 2011), especially with children with resistance to change or with negative experiences in learning, as it uses to be in the case of children with ADHD. Games can be offered as a natural way to stimulate different cognitive processes, to enhance active and autonomous learning and to provide possible simulations that would be unachievable with other mediums. This way, they can be used as tools to encourage and facilitate mediation. Nevertheless, they have to be properly designed to avoid gamification pitfalls (Lee and Hammer, 2011).

With this idea in mind, starting from our tabletop experiences and taking Feuerstein's categories as a reference, we have made an in-depth study of the type of mediation appropriate for technology-supported activities, and whether it can be supported by the technology or not. We have arrived at a set of suggestions about the type of questions and requests that the mediator should make to encourage and to guide the learning process in technology-supported activities (see Table 5). In each case, mediation may be done either by a person (P), or the interactive game or the technology (T), or both (T-P). Besides, they are related to Feuerstein's categories. 
Table 5. Mediation suggestions proposed for technology-supported activities. Highlighted those where Technology $(\mathrm{T})$, and not only a person $(\mathrm{P})$, may contribute.

\begin{tabular}{|c|c|c|c|}
\hline & Mediation suggestions & Mediator & $\begin{array}{l}\text { Feuerstein's } \\
\text { categories }\end{array}$ \\
\hline \multirow[t]{3}{*}{ M.1. } & Instructions should always be clear. & T-P & \multirow{3}{*}{$\begin{array}{l}\text { Intentionality } \\
\text { and reciprocity }\end{array}$} \\
\hline & $\begin{array}{l}\text { It should be verified that children have understood the instructions and that } \\
\text { they are able to express what they have to do. }\end{array}$ & $\mathbf{P}$ & \\
\hline & Ask questions to help children focus their attention. & T-P & \\
\hline \multirow[t]{2}{*}{ M.2. } & Ask questions to help children understand the context. & T-P & \multirow{2}{*}{ Transcendence } \\
\hline & $\begin{array}{l}\text { Ask questions about the new principles that the children have connected } \\
\text { from their experience. }\end{array}$ & & \\
\hline \multirow[t]{2}{*}{ M.3. } & Ask the children why. & T-P & \multirow{2}{*}{ Meaning } \\
\hline & Ask the children for precision about what they think and its meaning. & $\mathbf{P}$ & \\
\hline \multirow[t]{8}{*}{ M.4. } & Adapt the tasks considering the age and experience of the children. & T-P & \multirow{8}{*}{$\begin{array}{l}\text { Feeling of } \\
\text { competence }\end{array}$} \\
\hline & Cheer up. & T-P & \\
\hline & $\begin{array}{l}\text { Ask how they make their decisions and how they have validated their } \\
\text { hypothesis. }\end{array}$ & $\mathbf{P}$ & \\
\hline & Ask the children how they make inferences and come to conclusions. & $\mathbf{P}$ & \\
\hline & Ask about the satisfaction of the result. & $\mathbf{P}$ & \\
\hline & Value positively a proper answer. & T-P & \\
\hline & $\begin{array}{l}\text { If the answer isn't correct, ask the children what they would do in case of } \\
\text { repeating the task. }\end{array}$ & T-P & \\
\hline & Give children the option to test it after having thought of an alternative. & T-P & \\
\hline M.5. & Ask about the causes and their relation with the consequences. & $\mathbf{P}$ & $\begin{array}{c}\text { Regulation and } \\
\text { control of } \\
\text { behavior }\end{array}$ \\
\hline \multirow[t]{2}{*}{ M.6. } & Encourage the children to think aloud (meta-cognition). & $\mathbf{P}$ & \multirow{2}{*}{$\begin{array}{l}\text { Sharing } \\
\text { behavior }\end{array}$} \\
\hline & $\begin{array}{l}\text { Ask what they would do differently next time and about other ways to } \\
\text { resolve the problem. }\end{array}$ & T-P & \\
\hline \multirow[t]{2}{*}{ М.7 } & Ask the children to justify their answers. & T-P & \multirow{2}{*}{$\begin{array}{c}\text { Individual and } \\
\text { physiological } \\
\text { differentiation }\end{array}$} \\
\hline & $\begin{array}{l}\text { Ask the children to express the difference between their responses and those } \\
\text { of others. }\end{array}$ & $\mathbf{P}$ & \\
\hline M.8. & Ask about the objective of the game, holding children's attention. & T-P & \\
\hline
\end{tabular}




\begin{tabular}{|c|c|c|c|}
\hline & Ask about the strategies used to achieve the game's goal. & $\mathbf{T}-\mathbf{P}$ & Planning \\
\hline \multirow[t]{3}{*}{ M.9. } & $\begin{array}{l}\text { Ask the children to express what new things they have done and what they } \\
\text { have created. }\end{array}$ & T-P & \multirow{3}{*}{$\begin{array}{l}\text { Challenge: } \\
\text { Search for } \\
\text { novelty and } \\
\text { complexity }\end{array}$} \\
\hline & $\begin{array}{l}\text { Ask the children to compare in order to discover what is new in their } \\
\text { answers, and to accept the change. }\end{array}$ & $\mathbf{P}$ & \\
\hline & Ask the children what new principles could be applied to new situations. & $\mathbf{P}$ & \\
\hline \multirow[t]{2}{*}{ M.10. } & $\begin{array}{l}\text { Ask the children what classification is being used and what this } \\
\text { classification implies. }\end{array}$ & T-P & \multirow{2}{*}{$\begin{array}{l}\text { Structural } \\
\text { change }\end{array}$} \\
\hline & Ask the children about other possible classifications or criteria. & & \\
\hline \multirow[t]{3}{*}{ M.11. } & Ask the children about the results they expect. & $\mathbf{P}$ & \multirow{3}{*}{$\begin{array}{c}\text { Search for an } \\
\text { optimistic } \\
\text { alternative }\end{array}$} \\
\hline & When children answer correctly, you must congratulate them & T-P & \\
\hline & $\begin{array}{l}\text { When they answer incorrectly, he/she/it must encourage them to continue } \\
\text { with the activity }\end{array}$ & T-P & \\
\hline
\end{tabular}

Looking at Table 5, it can be concluded that although the technology and digital activities cannot completely replace the person or educator, they can be properly designed to have a relevant role as a complement and help for the educators. From a mediation perspective, it is necessary that the activities fulfill the following requirements:

- The design of the technological interaction has to facilitate the maintenance of the attention and interest, favoring the regulation of the impulsivity (R11).

- The activity should stimulate interaction among peers and with the person that facilitates the mediation (R12).

- The technological design has to be flexible and allow positive intervention of the mediator if needed, adapting to the each specific situation of the learning process and of the child's attitude (R13).

These mediation recommendations are consistent with the PASS model. They favor the attention process since they orientate the cognitive activity and the required response, and facilitate selective attention together with resistance to distractions. Regarding planning, they focus on problem solving, impulse control and processing.

In the next section, all the recommendations will be gathered in a set of guidelines to design interactive games for children with ADHD. It will be seen that, although coming from the tangible area, they are quite general and applicable to the design of any interactive application.

\section{GUIDELINES TO DEVELOP INTERACTIVE GAMES FOR ADHD CHILDREN}

The recommendations obtained from those described in the previous sections are summarized in Table 6. Six of them come from the assessment of different interactive tangible activities carried out with ADHD children as described in section 3. The following four are taken from the study of information processing in ADHD children, more specifically from analyzing the PASS model. The last three have been obtained from the analysis of how effective educative mediation should be carried out, as presented in section 4.

A set of guidelines based on these recommendations is presented in section 5.1. The guidelines are compared with those found in the literature in Section 5.2. 
Table 6. Extracted recommendations

\begin{tabular}{|c|c|c|}
\hline Extracted from & \multicolumn{2}{|c|}{ Recommendation } \\
\hline \multirow{6}{*}{$\begin{array}{l}\text { Preliminary } \\
\text { study }\end{array}$} & $\mathrm{R} 1$ & Instructions have to be clear and offer the possibility of being replayed. \\
\hline & $\mathrm{R} 2$ & Objects have to be easily identifiable by the children. \\
\hline & $\mathrm{R} 3$ & When there is a limited time to complete a task, this has to be clearly indicated. \\
\hline & $\mathrm{R} 4$ & $\begin{array}{l}\text { The educator should be able to control the whole game, jncluding the possibility } \\
\text { of repeating every task. }\end{array}$ \\
\hline & R5 & $\begin{array}{l}\text { Consider carefully the number of elements to memorize and the time to assimilate } \\
\text { them. The time should be established by the educator. }\end{array}$ \\
\hline & R6 & The game should promote collaboration to solve the problems. \\
\hline \multirow{5}{*}{$\begin{array}{l}\text { ADHD children } \\
\text { information } \\
\text { processing } \\
\text { (PASS) }\end{array}$} & R7 & Focus specifically on selective attention and planning. \\
\hline & $\mathrm{R} 8$ & $\begin{array}{l}\text { Design activities that bring cognitive challenges to the children, stimulating their } \\
\text { attention and their development potential. }\end{array}$ \\
\hline & $\mathrm{R} 10$ & $\begin{array}{l}\text { Make the most of the manipulative possibilities of the tabletop as a resource to } \\
\text { favor learning, interest, involvement and motivation of the children. }\end{array}$ \\
\hline & $\mathrm{R} 11$ & $\begin{array}{l}\text { The design of the technological interaction has to facilitate the maintenance of the } \\
\text { attention and interest, favoring the regulation of the impulsivity. }\end{array}$ \\
\hline & & \\
\hline
\end{tabular}




\begin{tabular}{|l|l|l|}
\hline $\begin{array}{c}\text { Effective } \\
\text { mediation }\end{array}$ & R12 & $\begin{array}{l}\text { The mediation should stimulate interaction among peers and with the person that } \\
\text { facilitates the mediation. }\end{array}$ \\
\cline { 2 - 3 } & R13 & $\begin{array}{l}\text { The technological design has to be flexible and allow positive intervention of the } \\
\text { mediator if needed, adapting to the each specific situation of the learning process } \\
\text { and of the child's attitude. }\end{array}$ \\
\hline
\end{tabular}

\subsection{Design guidelines}

The guidelines recommended to design interactive activities for children with ADHD are presented below. These guidelines have their origin in the previously identified recommendations and give support to the mediation suggestions presented in Table 5. The benefits for ADHD children, including those deriving from the support of a proper mediation process, are also listed.

\section{G1. The level of difficulty of the game should be adaptable.}

It is necessary to allow the time and effort needed to fulfill a task to be adaptable to the specific characteristics of the child playing. In particular, the number and type of elements to memorize and the time given to the child to assimilate them has to adaptable and modulated by the educator.

Origin: this guideline is based on the problems identified during the evaluation sessions (section 3) regarding the elements and the time needed to memorize them. As a result, it was recommended to give children enough time to assimilate the information, allowing the educator to set the time (recommendation R5).

Benefits: Selective attention and concentration will be facilitated. Active engagement will be promoted (mediation M1: intentionality and reciprocity), as well as an improvement in the feeling of competence (M.4) and, indirectly, in the planning competence (M.8).

\section{G2. The objective of the game and how to achieve it have to be clear.}

The instructions have to be clear and re-playable and should precisely express intermediate states during the game and final results. The game must allow the child to have all the information relating to the game at any moment to be able to decide and plan.

Origin: this guideline is based on the problems that children had in the evaluation when trying to understand and complete the activities. This could be because they were not paying attention to the instructions (for example, missing audio instructions) or because they did not know how to play because the instructions were not clear. This guideline covers the recommendation of giving initial clear instructions (R1), but applies to all the phases of the game.

Benefits: Giving all the information the child needs allows him/her to work on sustained attention together with the strategies needed to solve the activity (M.8. Planning). It also favors transcendence (M.2), meaning (M.3), the child's feeling of competence (M.4) and his/her engagement (M.1. intentionality and reciprocity).

\section{G3. The game should help the children be aware of the time.}


When there is limited time to complete a task, this has to be clearly indicated. Moreover, the time left to complete it should also be indicated.

Origin: this guideline is based on the problem detected in the evaluation regarding the lack of reaction to a limited time: the children, not knowing the time limitation, let the time pass by without doing anything. This resulted in the recommendation of clearly indicating the time assigned to a task, or the time remaining to complete it (R3).

Benefits: this would favor autonomy (M.4. feeling of competence), since the child has to connect with the consequences of the use of time from a perspective of causes and consequences. This way, the focus will be on the planning of the task and on the strategies needed to solve it (M.8. planning) and on the self-control required (M.5. regulation and control of behavior).

\section{G4. The manipulative possibilities of the tabletop should be potentiated.}

Interaction with physical objects should be promoted, but it is necessary to adapt these objects to the experience and age of the children. Changes in the object attributes (size, shape, direction, number) should be avoided during the game.

Origin: this guideline is based on the study of children with ADHD (R10), and on the problems detected during the evaluation sessions in the identification of certain objects which resulted in the recommendation of paying special attention in designing objects that can be easily identified (R2).

Benefits: manipulative materials are appealing to children and increase interest and motivation, activating the attention process. If objects are adapted to the context and age of the children, their feeling of competence (M.4) will be enhanced. Changes in the object attributes allow transcendence to be worked (M.2).

\section{G5. The game should be totally controllable by the educator}

The educator must be able to freeze the game until certain data is provided, a consensus is achieved, or the child calms down or rests. Moreover, it should be possible to redo an activity either because the child has failed or the educator considers it is appropriate.

Origin: this guideline is based on the study of mediation (R13) and on the problems detected during the evaluation when, after completing activities, it was necessary or desirable to play again. The detection of this problem resulted in the recommendation of giving the educator total control over the game (R4) to facilitate the adaptation to each child and situation.

Benefits: the possibility of "freezing" the game is an essential support for the educator throughout the mediation process.

\section{G6. The game should promote the search for information and the identification of alternatives.}

The search for information should be promoted by the game when players are asked to make a decision. This can be done by asking them to look for information that is relevant for the decision. Even if the answer is correct, the game should ask the children about other ways of performing the task and about the reasons for their action.

Origin: this guideline arises from the analysis of the specific needs of children with ADHD (R9) in relation with the improvement of their planning skills, and from the recommendation that the technological interaction should stimulate learning and all the processes involved (R11).

Benefits: The reflection about possible alternatives of performing the activity (M6. sharing behavior), anticipating possible consequences in the context, also allows transcendence to be worked (M.2). Besides, if done before 
acting, it would help self-control (M.5. regulation and control of behavior). During the activities, it would be interesting to ask the children what they are thinking and why (M.3 meaning), to encourage them to express the relationship between the planning and the goal (M.8 planning), and to make them think about other ways to achieve the goal based on different criteria (M.10 structural change).

\section{G7. Positive and encouraging feedback must always be given.}

Positive feedback to correct answers must always be given. In the case of negative answers, visual or verbal feedback should also be given to encourage the child and give him/her the opportunity of repeating the task.

Origin: this guideline arises from certain needs of the children with ADHD (R13) related to the need to enhance their feeling of competence, but it is also related to some of the recommendations extracted from the evaluation of the activities, such as allowing tasks to be repeated when needed (R4).

Benefits: By making use of positive feedback, the game can directly influence the child's feeling of competence (M.4), creating better expectations and improving the child's motivation (M1 intentionality and reciprocity). Encouraging the child in the case of negative answers supports the search for an optimistic alternative (M11).

\section{G8. Interest and motivation should be maintained through several stimuli.}

The stimuli must be chosen taking into account the children's interests and needs, as well as the activities and games.

Origin: this guideline arises from the analysis of the needs of children with ADHD (R10), in terms of attracting and holding their attention, learning to select the correct stimuli at any moment, and also from the recommendations about orientating technological interactions (R11), the interaction with people (R12) and the flexibility of the process (R13).

Benefits: conservation of the goal, planning and sustained attention. When the stimuli connect with the interests of the children, they allow transcendence (M.2) and their feeling of competence (M.4) to be worked.

\section{G9. Games should enhance selective attention.}

Stimuli should be used to focus attention. The game should lead children to focus their attention on a particular characteristic that differentiates one element from all the others.

Origin: this guideline arises from the analysis of the needs of children with ADHD (R7), since one of the children's main problems is their lack of selective attention. Benefits: improvement of selective attention and planning (M.8) as the child has to define objectives and select strategies to differentiate elements and fulfill the task.

\section{G10. The game should promote collaboration to solve the problems.}

Children have to be encouraged to interact with others. The game should foster joint resolution of problems.

Origin: this guideline arises from the problems detected during group play in the preliminary study (R6) as well as from the analysis of the needs of children with ADHD (R9 and R12) relating to the considerable benefits of social interaction, as well as the need to focus attention and suggest new possibilities.

Benefits: Metacognition will be stimulated through interaction, since it enriches the decision-making process by adding different perspectives (M.6. sharing behavior). Expressing aloud to others requires self-regulation, which improves the control of impulsivity (M.5. regulation and control of behavior) and may reveal divergences that 
help children work individual and psychological differentiation (M.7). Moreover, through collaboration and interaction with other children, the game can foster flexibility in accepting new alternatives (M.9. challenge: search for novelty and complexity).

\subsection{Discussion: Similarities and differences with other guidelines in the literature}

It is interesting to compare our guidelines with the other principles and guidelines found in the literature and summarized in Table 1. As stated in Section 2.2, the basic guidelines for usability and interaction should always be a reference for achieving well-designed applications. This is why we have also checked if our guidelines are consistent with the general principles of interaction design (Nielsen, 1994). The results of these comparisons are presented in Table 7. 
Table 7. Summary of the proposed guidelines compared to others found in the literature and to Nielsen's heuristics.

\begin{tabular}{|c|c|c|}
\hline Proposed Guideline & $\begin{array}{l}\text { Correspondence with other } \\
\text { authors' guidelines }\end{array}$ & $\begin{array}{c}\text { Correspondence with Nielsen's } \\
\text { Heuristics }\end{array}$ \\
\hline $\begin{array}{l}\text { G1. The level of difficulty of } \\
\text { the game should be adaptable. }\end{array}$ & $\begin{array}{l}\text { P1. Design simple games that do not } \\
\text { require much time commitment, } \\
\text { concentration or complex cognitive } \\
\text { abilities }\end{array}$ & $\begin{array}{l}\text { N7. Flexibility and efficiency of } \\
\text { use }\end{array}$ \\
\hline $\begin{array}{l}\text { G2. The objective of the game } \\
\text { and how to achieve it have to } \\
\text { be clear. }\end{array}$ & $\begin{array}{l}\text { MK9. Use brief and clear } \\
\text { instructions. } \\
\text { P2. Give enough structure and } \\
\text { context instructions. } \\
\text { S1. Provide structure to facilitate } \\
\text { activities. }\end{array}$ & $\begin{array}{l}\text { N2. Mateh between system and } \\
\text { the real world }\end{array}$ \\
\hline $\begin{array}{l}\text { G3. The game should help the } \\
\text { children be aware of the time. }\end{array}$ & & N1. Visibility of system status \\
\hline $\begin{array}{l}\text { G4. The manipulative } \\
\text { possibilities of the tabletop } \\
\text { should be potentiated. }\end{array}$ & & \\
\hline $\begin{array}{l}\text { G5. The game should be totally } \\
\text { controllable by the educator. }\end{array}$ & $\begin{array}{l}\text { MK10. Allow ample rest periods and } \\
\text { exercise breaks }\end{array}$ & $\begin{array}{l}\text { N7. Flexibility and efficiency of } \\
\text { use }\end{array}$ \\
\hline $\begin{array}{l}\text { G6. The game should promote } \\
\text { the search for information and } \\
\text { the identification of } \\
\text { alternatives. }\end{array}$ & & \\
\hline $\begin{array}{l}\text { G7. Positive and encouraging } \\
\text { feedback must always be given. }\end{array}$ & $\begin{array}{l}\text { MK3. Provide a high-reinforcement } \\
\text { environment. } \\
\text { S3. Encourage praise and rewards. }\end{array}$ & N1. Visibility of system status \\
\hline
\end{tabular}


G8. Interest and the motivation should be maintained through several stimuli.
P4. Provide the child with diverse options to avoid the child getting bored quickly and to improve motivation.

G9. Games should enhance selective attention.

G10. The game should promote collaboration to solve the problems.

The comparison between our guidelines with Nielsen's ten heuristics shows that three of them are closely related to five of ours. More specifically, G1 and G5 are closely related with Nielsen's heuristic N7.Flexibility and efficiency of use, which indicates that there must be different levels for different kinds of users. In our particular case, either in G1 and G5, the system must be flexible enough to allow educators to control the game and to determine the level of difficulty. Our guideline G2 is related with Nielsen's heuristic N2. Match between system and the real world, which indicates that the system must speak the users' language (with concepts familiar to the user) and the information must appear in a natural and logical order. The only way to make clear the objective of the game and how to achieve it is by following real-world conyentions. Moreover, our guidelines G3 and G7 are closely related with Nielsen's heuristic N1.Visibility of system status, which indicates that the system should always keep users informed about what is going on, either the time left to complete a task or for giving feedback. However, in G7 we go further, pointing out that the system must give positive and encouraging feedback, since this is especially important for ADHD children. The five remaining guidelines, G4, G6, G8, G9 and G10 are very specific for tabletop design or the characteristics of ADHD children and cannot be directly related with any general interaction design rule.

In the comparison of our proposed guidelines (Table 4, column 1) with the specific guidelines for the design of applications for children with ADHD (Table 4, column 2), it can be seen that some of them (G1, G2, G5, G7, G8) are consistent with the guidelines from other authors. However, others (G3, G4, G6, G9 and G10) are lacking in the literature. It can also be obseryed that all our guidelines except one (G4) are not restricted to tangible tabletop activities and can be applied to any kind of technology-supported therapeutic mediated process.

The new guidelines proposed in this work try to enhance planning and attention abilities in ADHD children (Das and Misra, 2015), without reducing external stimulation (Cruickshank et al., 1961). We consider that to achieve learning improvements, the interventions should be based on the development of self-control and strategies, including emotional abilities (DuPaul et al., 2011). This is why we have considered it necessary to include in our guidelines interaction and cooperative learning and the contributions of cognitive psychology, in particular of the PASS model. In general, and compared to the design guidelines presented in other works, the proposed guidelines have two distinguishing features:

- They focus on the design of the application or game paying special attention to interaction.

- They prioritize the acquisition of self-control and emotional abilities, the game being responsible for favoring moments of reflection about the resolution process being carried out by the child. 
Having drafted the guidelines, we decided to apply them to the design of activities for our tangible tabletops with the children from Atenciona in mind.

\section{DESIGNING AND TESTING TANGIBLE TABLETOP ACTIVITIES FOR ADHD CHILDREN: APPLYING THE GUIDELINES}

In this section, two NIKVision tabletop activities specially aimed at ADHD children are described in detail, taking into account the guidelines discussed above. The results obtained in the assessment of both activities with ADHD children are then presented.

\subsection{Designing two new tangible tabletop activities}

As stated in the preceding section, it is essential to allow the educator to have entire control of the activities (G5) and of the time to perform each of them (G3). Therefore, it was decided to add a menu bar (see Figure 3 left) to facilitate navigation between the activities and the different activity levels. Educators may also use this button to pause the activity if a child requires more time or if it is necessary for him/her to mediate. For example, before beginning to play, the educator may ask the children about the objective of the activity (G2) and motivate the child to explain how he/she will do the activity (G6). It also allows returning to the beginning of the activity (home button) and repeating the instructions. This menu bar was incorporated into both games and is located in the lower part of the screen. The educator can control the menu by means of a couple of new tangible objects (Figure 3 right).

All the activities give a positive audio feedback when children perform the task correctly (G7). However, if the children fail, the audio feedback is conceived as a positive reinforcement, encouraging them to repeat the activity and continue playing.

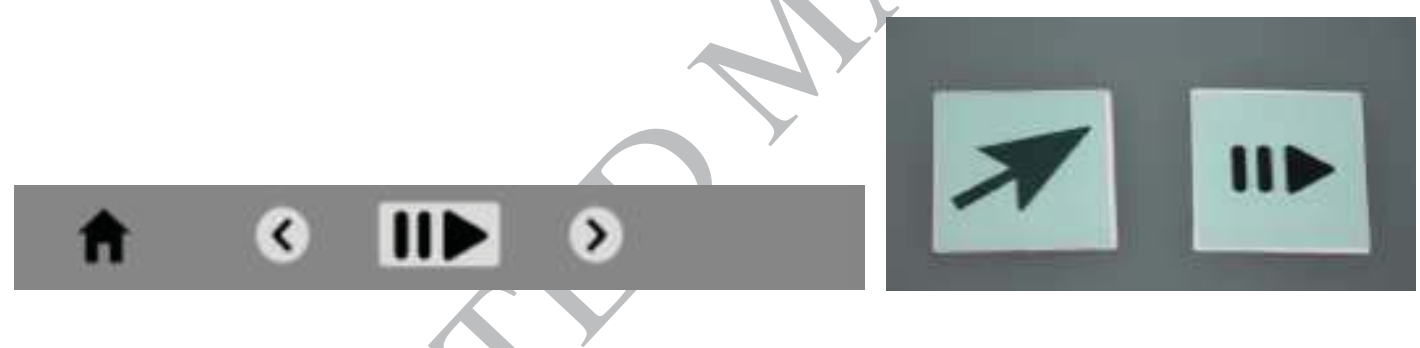

Fig.3. Left: Menu bar - Right: Physical objects for controlling the activities

The two activities developed for ADHD children, called "Shapes and colors" and "Once upon a time...", are presented below. For each one, there is a brief description of the activity, focusing on the guidelines applied, and an explanation of its intervention goals.

\subsection{1 'Shapes and colors'}

Activity description: 'Shapes and colors' is a memory game designed to be played by 2, 3 or 4 children (G10). The educator can choose to let the children read the instructions or to listen to them. At the beginning of the activity, the tabletop surface shows a green grid with several figures placed on different grid positions (see Figure 4 left). After several seconds (established by the educator - G3), the figures disappear and the child has to remember which figure (and color) was in each square. The physical objects (G4) are bracelets with a picture of a figure or a color (see Fig.4 right) that have to be worn by the children. The children have to place their hands on the square on which appears the figure with the same shape and color as that shown on the bracelet they are wearing. 

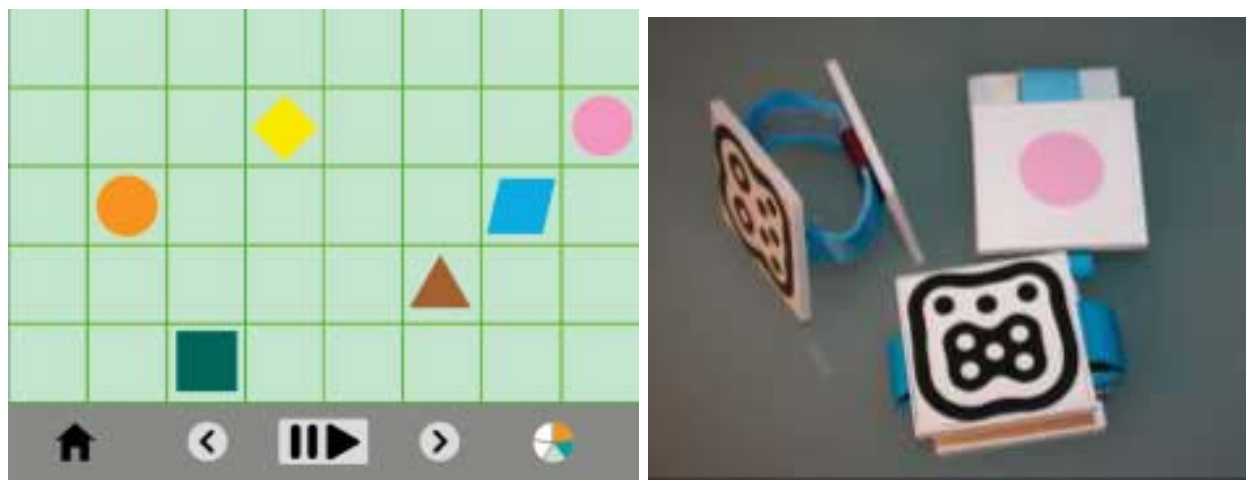

Fig. 4. Left: "Shapes and colors" game board. Right: Bracelets used in the activity.

The activity begins with a set of figures with the same shape but different colors. The difficulty of the task gradually increases (G1) by showing different geometrical shapes with different colors (there are 10 levels of difficulty). In all the tasks, there is at least one figure that does not appear on the bracelets and that acts as a 'distractor' to foster selective attention (G9). The educator can stop the game at any time (G5) to discuss progress with the children, trying to promote reflection about the achievement of the activity's goal (G6).

Intervention goals: The possibility of using objects attached to the hands instead of a finger to interact with the table allows working abilities such as bilateral coordination (use of the two hands) and the coordination of the upper body. These abilities are essential for daily life, since most of the activities that we do involve the use of both hands. The game helps children to work with their laterality, making them differentiate their left hand from their right hand, since when two children play together each child wears two different bracelets: one on his/her right hand and the other on his/her left hand. The child has to pay attention not just to the figure but also to the hand where the picture is, in order to correctly place the hand on the square.

This game also involves the use of memory, but in a complex manner, since not only a color or a shape but also its location must be remembered. In this way, spatial reasoning is favored, which it is important to potentiate at an early age.

\subsection{2 'Once upon a time...'}

Activity description: 'Once upon a time...' is a game for improving reading and listening comprehension. As in the previous activity, just before beginning to play the educator can choose between making the children listen to the instructions or read them and they can be replayed as many times as wanted (G2).

At the beginning, two tales are presented on the surface of the tabletop: 'The sleepyhead dragon' and 'Uga, the turtle' (Fig 5 left). The educator will usually choose between the two different stories that the children have to listen to or to read. This game can be played individually or by several children using different toys related to the stories (Fig 5 right). In the latter case, the game is performed collaboratively (G10). In contrast to the previous activity in which children have a limited amount of time to finish, in this case children can take all the time they need to read the story and, when they finish, the educator can continue with the activity (G1). 

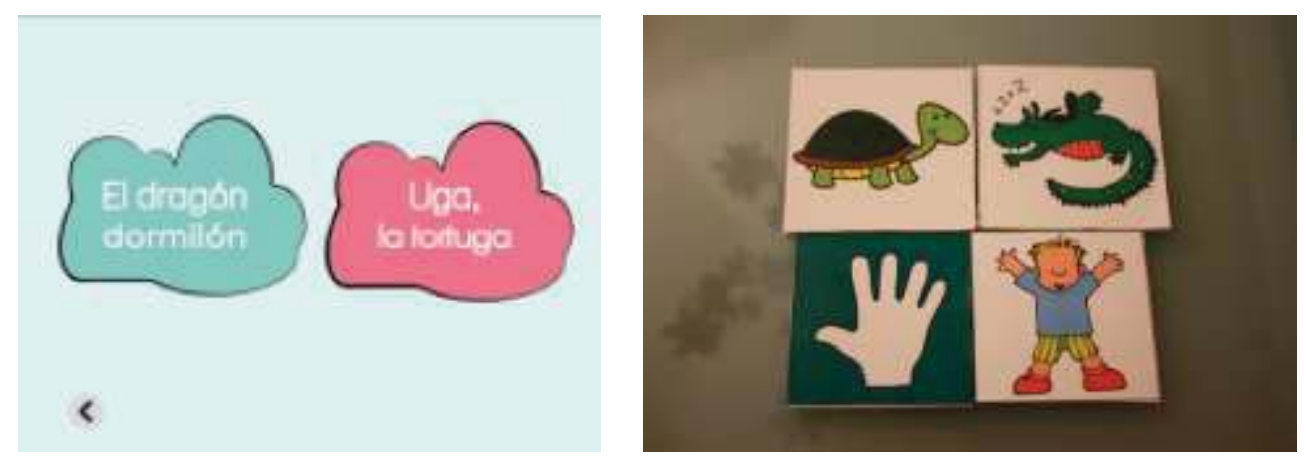

Fig. 5. Left: Activity "Once upon a time..." Right: Tangible objects used in the activity.

Once the story has been listened to or read (see Fig.6 left), a set of questions is displayed to see if the children have paid attention to the story (G9) (see Fig.6 right). In this case, the level of difficulty of the game lies in the questions that are asked about the story (G1). For all the questions there are at least two different answers and the child has to choose the correct one (G9). In order to answer the questions, several tangible playing pieces (G4) (see Fig.6 right) are used to indicate the correct answer. When the children respond correctly, a "correct" sound is reproduced. Otherwise, they hear a "wrong" sound followed by a phrase that encourages the children to try again (G7). The game may be stopped by the educator at any time to promote discussion and reflection about the answers given by the children (G6).
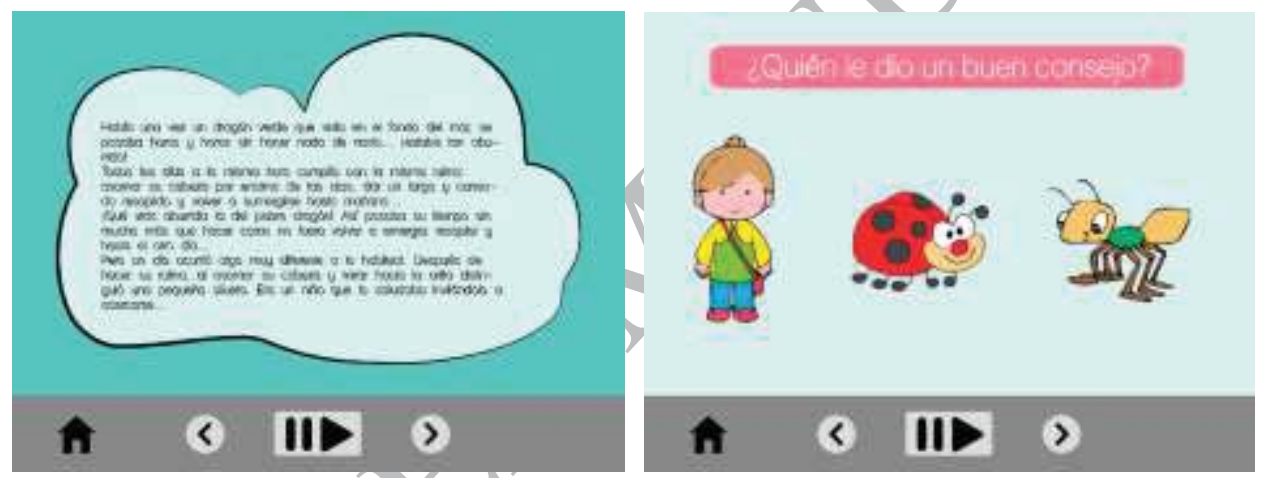

Fig. 6. Left: Story “Uga, the turtle”. Right: Question 'Which character gave the turtle good advice?'

Intervention goals: This activity includes written texts that the children can read or listen to, working on reading or listening comprehension, respectively. They must select the correct answers about these texts, so that they must work semantic processing. This semantic processing requires the use of the planning system, the use of previous knowledge, and simultaneous processing. As in other tasks, their attention, and especially selective attention, is essential.

\subsection{Testing the new activities in Atenciona}

Once the activities were developed following the previously explained guidelines, we proceeded to test them at the Atenciona association. The objective of this evaluation was to analyze the usefulness of the applied guidelines and also to detect usability problems in order to refine or adapt the guidelines where necessary.

As in the previous evaluations (Section 3.3) the method followed in the evaluation was observational. This time 10 of the children whose characteristics are set out in Table 3, one girl and nine boys aged from 7 to 12, participated in the session. They were organized into two groups of four children and one group of two. Each group participated in one session of around 30 minutes. First, they played the "Shapes and colors" game (each of the four children wearing a bracelet with a shape and color) after which they played the "Once upon a time..." 
game in pairs. The last group (a couple) played the "Once upon a time..." game only. As in the previous session the educators, a NIKVision expert and a psychologist were present. During the observation, notes were taken by the psychologist and the expert on the actions and reactions of the children while playing, focusing on the impact of the proposed guidelines. After the evaluation, the educators were interviewed about their perception of the experience with the new activities and with the new mediation support.

Some conclusions have been extracted from the interviews with the educators and the notes taken during the sessions about the design considerations taken into account when developing the two activities. The conclusions are presented below, including some representative comments extracted from the interviews:

- The game experience was very well received by the educators: "At first it was difficult for some children to get used to the tabletop, but after some screens they were able to interact with it with ease" (notes); "Despite being with a child that didn't stop jumping, apparently not paying much attention, she was able to solve the activities successfully" (notes).

- The educators made extensive use of the facility to adapt the level of difficulty of "Shapes and colors" (G1): when they saw that children performed the first tasks too quickly, they selected the last ones which were the most difficult.

- The possibility of "traveling" between tasks and of being able to return to the beginning of the activity without having to interrupt and restart the game (G5) saved a lot of time. "It is good to be able to stop the game and restart it to read the instructions again in case the child has doubts. It is well designed to deal with planning" (interview). Besides, it also prevents the child from feeling frustrated, since before adding this possibility the child had to repeat the tasks that he/she had already done until reaching the task that he/she wanted to revise.

- The possibility of controlling the game (G5), giving more time when needed, was also appreciated: "If he is provided with enough time to think, he performs all the activities correctly. He just needs time to think" (note).

- The opportunity for the children to be autonomous and to be able to decide to read or listen to the instructions again was well received (G2): "When there are two or three instructions, the child forgets the order and reads the indication autonomously" (notes).

- Both games motivated the children to collaborate, since the "Shapes and Colors" game cannot be completed until each one of the four children has his/her hand placed over the corresponding square, and in the "Once upon a time" game the answer to the question cannot be given until both children discuss the correct answer (G10). This last aspect reduced trial and error, since the educator stopped the game (G5) and did not allow an answer to be given until the children had reasoned together (G6). Some positive behaviors were documented: "The toys are distributed by turns" (notes), "Children talk to each other and take a common decision" (notes). However, some negative behaviors were also noted: "He is unable to give his partner enough time to think about the solution before answering himself, or in case of waiting he does it without stopping shouting: 'Please, I know it, I know it!' and jumping" (notes); "Children argue about who should control the manipulative toy" (notes).

- The manipulative characteristics of the tabletop were recognized as a motivating element (G4): "Working with the tabletop is very interesting since it is something innovative, visual and manipulative" (interview).

The evaluation has also been useful for detecting some usability problems in the design of the activities:

- Some colors in the "Shape and Colors" activity were too similar and children mistook them when playing. This has to be considered when using color as the stimulus to focus attention (G9).

- The vocabulary used in the game instructions was sometimes too difficult and the instructions too long so that children stopped listening and/or reading them. This has to be considered when stating the objective of the game (G2). 
- The educators (and the children) were sometimes "lost" in the game structure, not remembering the order of the tasks in the games. This has to be considered to make the game more easily controllable by the educator (G5).

- In the "Once upon a time" game legibility problems on the table arose and strong differences in reading comprehension levels among children of similar ages were detected, making the game difficult for some of the children. These problems have to be taken into account when establishing the goal of the game (G2) and its level of difficulty (G1).

- Despite the positive feedback (G7), some children asked the educator for verbal or gestural indications to confirm that he/she had given the correct answer.

These problems have allowed us to extract some additional recommendations to apply the guidelines successfully (in italics):

- G1. The level of difficulty of the game should be adaptable.

It is necessary to be able to adapt the time and effort needed to fulfill a task to the specific characteristics of the child playing. In particular, the number and type of elements to memorize and the time given to the child to assimilate them has to adaptable and adjusted by the educator. Besides, if reading comprehension is involved in an activity it is necessary to introduce an adaptable level of difficulty in the activity. This adaptation can be used for working on the different levels of text comprehension (literal, inferential and critical).

- G2. The objective of the game and how to achieve it have to be clear.

The instructions have to be clear and re-playable and should precisely express intermediate states during the game and the final results. The game must allow the child to have all the information of the game at any moment to be able to decide and plan. The instructions must be short and the steps clear. It is necessary to pay attention to the vocabulary that is used so that children of diverse ages and reading comprehension levels can understand it. Legibility has to be assured.

- G5. The game should be totally controllable by the educator.

The educator must be capable of freezing the game until certain data is provided, a consensus is achieved, or the child calms down or rests. Moreover, it must be possible to redo an activity because either the child has failed or the educator considers it appropriate. To help control the game, it is necessary to indicate which task is being performed at any moment, and its position within the general structure of the game.

- G7. Positive and encouraging feedback must always be given.

It is necessary to reinforce positive feedback in the case of correct answers.

- G9. Games should enhance selective attention.

Stimuli should be used to focus attention. The game should lead children to focus their attention on a particular characteristic that differentiates one element from all the others. The use of color as a distinguishing characteristic should be avoided or else colors must be clearly distinguishable.

The evaluation has enabled the detection of strengths and weaknesses of the design and usability of the activities. Additionally, it has helped to reinforce the relevant role of the educator to facilitate the development process in the learning and to go further: "He needs the educator's help to associate concepts" (notes); "He associates concepts correctly with the mediator's help" (notes). This strengthens our idea that technology should complement the educator's role, whose task remains essential.

\section{CONCLUSIONS AND FUTURE WORK}

In spite of its prevalence in our societies, there is a lack of works focusing on ADHD children. There are very few works in the field of tangible interaction and none dealing with tangible tabletops despite the fact that these have proved to be quite successful with other children with learning difficulties. 
Following previous successful experiences with tangible tabletops and special educational needs children, the aim of the present work was to study how tangible tabletops could support therapeutic work with ADHD children. Collaboration with a regional association of ADHD families and professionals has enabled us to carry out a set of evaluation sessions with such children. The tabletop activities were motivating and attractive for the children and useful and interesting for professionals due to the possibility of working not only on cognitive skills (such as attention and planning) but on social skills, which are recognized as critical for these children. Nevertheless, some interaction problems were found during the evaluation sessions that led to a first set of recommendations concerning the activities to be performed with these children.

We realized that creating games that focus on the learning needs of children with ADHD is not an easy task, since it is required to delve deep into their cognitive and emotional processes. This led us to carry out an in-depth study of their specific needs, lacks and potentialities and of the necessary mediation process recognized by educators as a key factor in the success of education intervention. In fact, the need arose for designing activities to support and favor the learning process through appropriate mediation and a second group of recommendations was compiled.

As a result of our studies and experiences, we have drafted a set of ten guidelines for the design of interactive activities to be played on tangible tabletops by ADHD children. Only one of them is specific to tabletops while the others are wholly applicable to the design of interactive games and applications for ADHD children. Some of the guidelines are consistent with guidelines found in the literature but others were not found in previous works. Our guidelines focus on a proper design of interactions as a way of helping these children to acquire self-control, emotional and reflection capabilities.

Even though the guidelines have been established taking into account the learning needs of ADHD children, the fact that they favor the development of the cognitive functions relating to planning and attention make them suitable for application to other neurodiverse children (Dalton, 2013) with difficulties in those areas. Following this inclusive perspective (Miles and Singal, 2010; Ainscow, 2005), the mediation recommendations may be also considered as a framework to be adapted to the specific characteristics of each child or group of children.

As future work, we are planning to carry out a participatory design activity with the children of the Atenciona association, as they were highly motivated by the tabletop. Such an activity will allow working not only on their creativity and technical skills, but also their social abilities, as group work will be needed. This could be a very positive experience for these children. Besides, it will help to obtain interesting research information and redress the lack of such experiences in the literature, as stated in (Börjesson, 2015). In fact, Börjesson et al. give useful recommendations that will be of great help when designing and developing future experiences.

We hope our work will help to put these children into the framework of interaction research so that they can benefit from the potential of the new interaction paradigms.

\section{ACKNOWLEDGMENTS}

We want to thank Leire Gil and the Atenciona association for their collaboration in this work. This work has been partly financed by the Spanish Government and the European Union through the contract TIN2015-67149-C3-1R (MINECO/FEDER) and by the Aragonese Government and the UE through the FEDER 2014-2020 “Construyendo Europa desde Aragón” action (Group T25_17D).

\section{REFERENCES}

ACTIVATETM cognitive brain training program: http://www.c8home.com (accessed 28.06.18)

ADDitude: http://www.additudemag.com (accessed 19.12.17) 
Ainscow, M., 2005. Developing inclusive education systems: what are the levers for change?. Journal of educational change. 6(2), 109-124.

Akinbami, L. J., Liu, X., Pastor, P. N., Reuben, C. A., 2011. Attention Deficit Hyperactivity Disorder among Children Aged 5-17 Years in the United States, 1998-2009. NCHS Data Brief. Number 70. Centers for Disease Control and Prevention.

Alessandrini, A., Cappelletti, A., Zancanaro, M., 2014. Audio-augmented paper for therapy and educational intervention for children with autistic spectrum disorder. International Journal of Human-Computer Studies, 72(4), 422-430.

Antle, A.N. 2009. Embodied child computer interaction -- Why embodiment matters, ACM Interactions, March+April Issue (2009), 27-30.

Antle, A. N., Wang, S., 2013. Comparing motor-cognitive strategies for spatial problem solving with tangible and multitouch interfaces. In Proceedings of the 7th International Conference on Tangible, Embedded and Embodied Interaction, TEI'13. ACM, New York, NY, USA, pp. 65-72.

Arnaud, A., Corrégé, J. B., Clavel, C., Gouiffès, M., Ammi, M., 2016. Exploration of virtual environments on tablet: comparison between tactile and tangible interaction techniques. In Proceedings of the 18th ACM International Conference on Multimodal Interaction, ICMI'16. ACM, New York, NY, USA, pp. 357-361.

Ayllon, T., Roberts, M. D., 1974. Eliminating discipline problems by strengthening academic performance. Journal of Applied Behavior Analysis. 7, 71-76.

Barkley, R.A., 2006. Attention-Deficit Hyperactivity Disorder: A Clinical Workbook, Vol. 2. New York: The Guilford Press. Bauermeister, J. J., Matos, M., Reina, G., Salas, C. C., Martínez, J. V., Cumba, E., Barkley, R. A., 2005. Comparison of the DSM-IV combined and inattentive types of ADHD in a school-based sample of Latino/Hispanic children. Journal of Child Psychology and Psychiatry. 46, 166-179.

Bauermeister, J.J., Barkley, R.A., Bauermeister, J.A., Martínez, J.V., McBurnett, K. 2012. Validity of the sluggish cognitive tempo, inattention, and hyperactivity symptom dimensions: neuropsychological and psychosocial correlates. Journal of abnormal child psychology, 40(5), 683-697

Bonillo, C., Baldassarri, S., Marco, J., Cerezo, E. 2017. Tackling developmental delays with therapeutic activities based on tangible tabletops. Universal Access in the Information Society, 1-17.

Bonillo, C., Cerezo, E., Marco, J., Baldassarri, S. 2016. Designing Therapeutic Activities Based on Tangible Interaction for Children with Developmental Delay. In International Conference on Universal Access in Human-Computer Interaction (pp. 183-192). Springer, Cham.

Börjesson, P., Barendregt, W., Eriksson, E., Torgersson, O., 2015. Designing technology for and with developmentally diverse children: a systematic literature review. In Proceedings of the 14th International Conference on Interaction Design and Children, IDC 15. ACM, New York, NY, USA, pp. 79-88.

Bul, K.C., Kato, P.M., Van der Oord, S., Danckaerts, M., Vreeke, L. J., Willems, A.J.J., van Oers, H.J.J., Van Den Heuvel, MSc. R., Birnie, D.M.D. Van Amelsvoort, T., Franken, I.H.A., Maras, A., 2016. Behavioral outcome effects of serious gaming as an adjunct to treatment for children with attention-deficit/hyperactivity disorder: a randomized controlled trial. Journal of medical Internet research. 18(2).

Cerezo, E., Marco, J., Baldassarri, S., 2015. Hybrid Games: Designing Tangible Interfaces for Very Young Children and Children with Special Needs. In: Nijholt A. (eds) More Playful User Interfaces. Gaming Media and Social Effects. Springer, Singapore, pp. 17-48.

Cohen, L.; Manion, L. y K. Morrison (2007) Research Methods in Education. New York, Routledge. 
Cruickshank, W.M., Bentsen, F.A., Ratzenburg, F.A. Tannhauser, M.T., 1961. A Teaching Method for Brain Injured Children: A demonstration-pilot study (Vol. 6), Syracuse, New York: Syracuse University Press.

Dalton, S., 2013. Neurodiversity HCI. interactions, 20(2), 72-75.

Das, J.P., Misra, S.B. 2015. Cognitive Planning and Executive functions. London: Sage.

Dourish, P. 2004. Where the action is: the foundations of embodied interaction. MIT press.

DuPaul, G.J. Weyandt L.L., Janusis, G.M. 2011 ADHD in the Classroom: Effective Intervention Strategies, Theory Into Practice, 50(1), 35-42.

Erhel, S., Jamet, E., 2013. Digital game-based learning: Impact of instructions and feedback on motivation and learning effectiveness. Computers \& Education. 67, 156-167.

Falcão, T. P., Price, S. 2010. Informing design for tangible interaction: a case for children with learning diffieulties. In Proceedings of the 9th International Conference on Interaction Design and Children (pp. 190-193). ACM.

Farr, W., Price, S., Jewitt, C. 2012. An introduction to embodiment and digital technology research: Interdisciplinary themes and perspectives.

Farr, W., Yuill, N., Harris, E., Hinske, S. 2010. In my own words: configuration of tangibles, object interaction and children with autism. In Proceedings of the 9th International Conference on Interaction Design and Children (pp. 30-38). ACM.

Feuerstein, R., Rand, Y., Hoffman, M.B. Miller, R., 1980. Instrumental Enrichment and intervention program for cognitive modifiability. Baltimore: University Park Press.

Feuerstein, R., Klein, P. S., Tannenbaum, A. J. (Eds.), 1991. Mediated learning experience (MLE): Theoretical, psychosocial and learning implications. Freund Publishing House Ltd..

Frith, C.D., 2012. The role of metacognition in human social interactions. Fil. Trans. R. Soc. B. 367 (1599), $2213-2223$.

Garcia, J. J., de Bruyckere, H., Keyson, D. V., Romero, N., 2013. Designing personal informatics for self-reflection and selfawareness: the case of children with attention deficit hyperactivity disorder. In International Joint Conference on Ambient Intelligence, pp. 109-123. Springer, Cham.

Goh, W. B., Shou, W., Tan, J., Lum, G. T., 2012, Interaction design patterns for multi-touch tabletop collaborative games. In CHI'12 Extended Abstracts on Human Factors in Computing Systems, CHI EA'12. ACM, New York, NY, USA, pp. 141150 .

Graham, J., Banaschewski, T., Buitelaar, J., Coghill, D., Danckaerts, M., Dittmann, R. W., et al., 2011. European guidelines on managing adverse effects of medication for ADHD. European child \& adolescent psychiatry. 20(1), 17-37.

Granic, I., Lobel, A., and Engels, R. C., 2014. The benefits of playing video games. American Psychologist. 69(1), 66.

Guía, E., Lozano, M. D., Penichet, V. M., 2015. Educational games based on distributed and tangible user interfaces to stimulate cognitive abilities in children with ADHD. British Journal of Educational Technology, 46(3), 664-678.

Gunter, B., 1998. The effects of video games on children: The myth unmasked. A\&C Black.

Hallahan, D. P., Kaufman, J. M., 1976. Introduction to learning disabilities. Englewood Cliffs, New Jersey: Prentice-Hall.

Haring, P., Chakinska, D., Ritterfeld, U., 2011. Understanding serious gaming: A psychological perspective. Handbook of research on improving learning and motivation through educational games: Multidisciplinary approaches. 1, 413-430.

Healy, J. M. 1999. Failure to connect: How computers affect our children's minds--for better and worse. Simon and Schuster. 
Hendrix, K., van Herk, R., Verhaegh, J., and Markopoulos, P., 2009. Increasing children's social competence through games, an exploratory study. In Proceedings of the 8th International Conference on Interaction Design and Children, IDC '09. ACM, New York, NY, USA, pp. 182-185.

Horn, M. S., Crouser, R. J., Bers, M. U. 2012. Tangible interaction and learning: the case for a hybrid approach. Personal and Ubiquitous Computing, 16(4), 379-389.

Ishii, H., Ullmer, B., 1997: Tangible Bits: Towards Seamless Interfaces between People, Bits and Atoms. Proceedings of the ACM SIGCHI Conference on Human factors in computing systems, CHI '97. ACM, New York, NY, USA, pp. $234-241$.

Iwata, T., Yamabe, T., Polojärvi, M., Nakajima, T., 2010. Traditional games meet ICT: a case study on go game augmentation. In Proceedings of the fourth international conference on Tangible, embedded, and embodied interaction, TEI '10. ACM, New York, NY, USA, pp. 237-240.

James, W.,1890. The principles of psychology. New York: Holt.

Juguemos. https://www.researchgate.net/project/TIN2015-67149-C3-2-R-JUGUEMOS (accessed 19.12.17)

Kaltenbrunner, M., Bencina, R., 2007. reacTIVision: a computer-vision framework for table-based tangible interaction. In Proceedings of the 1 st international conference on Tangible and embedded interaction, TEI '07. ACM, New York, NY, USA, pp. 69-74.

Kawulich, B. 2005. "La observación participante como método de recolección de datos" en Qualitative Social Research, vol.6, no 2, pp.1-32. http://www.qualitativeresearch.net/index.php/fqs/article/viewArticle/466/ 998

Lahey, B. B., Stempniak, M., Robinson, E. J., Tyroler, M. J. 1978. Hyperactivity and learning disabilities as independent dimensions of child behavior problems. Journal of Abnormal Psychology. 87(3), 333.

Lechelt, Z., Rogers, Y., Yuill, N., Nagl, L., Ragone, G., Marquardt, N, 2018. Inclusive Computing in Special Needs Classrooms: Designing for All. In Proceedings of the 2018 CHI Conference on Human Factors in Computing Systems (p. 517). ACM.

Lee, J. J., Hammer, J. 2011. Gamification in education: What, how, why bother?. Academic exchange quarterly, $15(2), 146$.

Li, Y., Fontijn, W., and Markopoulos, P., 2008. In Proceedings of the 2nd International Conference on Fun and Games, Panos Markopoulos, Boris Ruyter, Wijnand Ijsselsteijn, and Duncan Rowland (Eds.). Springer-Verlag, Berlin, Heidelberg, pp. 182-193.

Mahapatra, S., 2016. Planning Behaviour in Good and Poor Readers. Journal of Education and Practice, 7(4), 1-5.

Mansor, E. I., De Angeli, A., and De Bruijn, O., 2008. Little fingers on the tabletop: A usability evaluation in the kindergarten. In Horizontal Interactive Human Computer Systems, TABLETOP'08. 3rd IEEE International Workshop on, pp. 93-96.

Marco, J., Baldassarri, S.,Cerezo, E. 2013. NIKVision: Developing a Tangible Application for and with Children. Journal of Universal Computer Science 19(15), 2266-2291.

Marco, J., Cerezo, E., Baldassarri, S., 2013b. Bringing tabletop technology to all: evaluating a tangible farm game with kindergarten and special needs children. Personal and ubiquitous computing, 17(8), 1577-1591.

Mayes, S. D., Calhoun, S. L., Crowell, E. W., 2000. Learning disabilities and ADHD overlapping spectrum disorders. Journal of learning disabilities. 33(5), 417-424.

McKnight, L., 2010. Designing for ADHD in search of guidelines. In IDC 2010 Digital Technologies and Marginalized Youth Workshop. 
Miles, S., Singal, N., 2010. The Education for All and inclusive education debate: conflict, contradiction or opportunity? International Journal of Inclusive Education. 14(1), 1-15.

Naglieri, J. A., Das, J. P, 1988. Planning-arousal-simultaneous-successive (PASS): A model for assessment. Journal of School Psychology, 26(1), 35-48.

Nielsen, J., 1994. Enhancing the explanatory power of usability heuristics. Proc. ACM CHI'94 Conf. (Boston, MA, April 2428), 152-158.

NIKVision: http://giga.cps.unizar.es/affectivelab/natural-interaction-info/. Last accessed: August 8, 2018

Piaget, J., Cook, M. 1952. The origins of intelligence in children (Vol. 8, No. 5, p. 18). New York: International Universities Press.

Piper, A. M., O'Brien, E., Morris, M. R., Winograd, T. 2006. SIDES: a cooperative tabletop computer game for social skills development. In Proceedings of the 2006 20th anniversary conference on Computer supported cooperative work (pp. 1-10). ACM.

Play Attention: http://www.playattention.com/ (accessed 28.06.18)

Price, S., Marshall, P. 2013. Designing for learning with tangible technologies. Handbook of Design in Educational Technology, 288.

Pykhtina, O., Balaam, M., Wood, G., Pattison, S., Olivier, P., 2012. Designing for Attention Deficit Hyperactivity Disorder in Play Therapy: the case of Magic Land.

Read, J. C., Markopoulos, P., 2013. Child-computer interaction. International Journal of Child-Computer Interaction, 1(1), 26.

Rizzo, A. A., Buckwalter, J. G., Bowerly, T., Van Der Zaag, C., Humphrey, L., Neumann, U., Chua, C., Kyriakakis, C., Van Rooyen, A., Sisemore, D., 2000. The virtual classroom: a virtual reality environment for the assessment and rehabilitation of attention deficits. CyberPsychology \& Behavior, 3(3), 483-499.

Rost, K.J., 1967. Academic achievement of brain injured and hyperactive children isolation. Exceptional children, 4(2), 125126.

Schöning, J., Hook, J., Bartindale, T., Schmidt, D., Oliver, P., Echtler, F., Motamedi, N., Brandl, P., von Zadow, U., 2010. Building interactive multi-touch surfaces. In Tabletops-Horizontal Interactive Displays. Springer London, pp. 27-49.

Shneiderman, B., 2010. Designing the user interface: strategies for effective human-computer interaction. Pearson Education India.

Sibley, M.H., Kuriyan, A.B., Evans, S.W., Waxmonsky, J.G. and Smith, B.H., 2014. Pharmacological and psychosocial treatments for adolescents with ADHD: An update systematic review of the literature. Clinical Psychology Review. 34, 218232 .

Sonne, T., MarshallP., Obel, C., Thomsen, P.H. Gronbaek, K., 2016. An Assistive Technology Design Framework for ADHD. I n Proceedings of the 28th Australian Conference on Computer-Human Interaction, OzCHI '16. ACM, New York, NY, USA, pp. 60-70

Story, M. F., Mueller, J. L., Mace, R. L., 1998. The universal design file: Designing for people of all ages and abilities.

Suárez, C. O., Marco, J., Baldassarri, S., Cerezo, E., 2011. Children with special needs: comparing tactile and tangible interaction. In: Campos P., Graham N., Jorge J., Nunes N., Palanque P., Winckler M. (eds) Human-Computer Interaction INTERACT 2011. INTERACT 2011. Lecture Notes in Computer Science, vol 6949. Springer, Berlin, Heidelberg, pp. 495 498 . 
Taddei, S., Contena, B., Caria, M., Venturini, E., Venditti, F., 2011. Evaluation of children with attention deficit hyperactivity disorder and specific learning disability on the WISC and Cognitive Assessment System (CAS). ProcediaSocial and Behavioral Sciences. 29, 574-582.

Tripathi, N., Hasan, M. 2014. Deficits in cognitive processes in children with ADHD. Indian Journal of Health and Wellbeing, 5(12), 1459.

Vygotsky L.S. 1996. Thought and language. The Massachusetts Institute of Technology: Massachusett.

Villafuerte, L., Markova, M., Jorda, S., 2012. Acquisition of social abilities through musical tangible user interface: children with autism spectrum condition and the reactable, In CHI'12 Extended Abstracts on Human Factors in Computing Systems, CHI EA’12. ACM, New York, NY, USA, pp. 745-760.

Weisberg, O., GalOz, A., Berkowitz, R., Weiss, N., Peretz, O., Azoulai, S., KoplemanRubin, D., Zuckerman, O., 2014. TangiPlan: designing an assistive technology to enhance executive functioning among children with ADHD. In Proceedings of the 2014 conference on Interaction design and children, IDC'14. ACM, New York, NY, USA, pp. 293-296

Zarin, R., Fallman, D., 2011. Through the troll forest: exploring tabletop interaction design for children with special cognitive needs. In Proceedings of the SIGCHI Conference on Human Factors in Computing Systems, CHI'11. ACM, New York, NY, USA, pp. 3319-3322.

Zuckerman, O., Arida, S., Resnick, M. 2005. Extending tangible interfaces for education: digital montessori-inspired manipulatives. In Proceedings of the SIGCHI conference on Human factors in computing systems (pp. 859-868). ACM.

Zuckerman, O., Gal-Oz, A., Tamir, N., Kopelman-Rubin, D. 2015. Initial validation of an assistive technology to enhance executive functioning among children with ADHD. In Proceedings of the 14th International Conference on Interaction Design and Children (pp. 299-302). ACM. 
Manuscript Title: Guidelines to Design Tangible Tabletop Activities for Children with Attention Deficit Hyperactivity Disorder

List of All Authors: Eva Cerezo, Teresa Coma, Ana Cristina Blasco, Clara Bonillo, Ma Ángeles Garrido, Sandra Baldassarri

Corresponding Author: Clara Bonillo

The authors declare that they have no significant competing financial, professional, or personal interests that might have influenced the performance or presentation of the work described in this manuscript. 


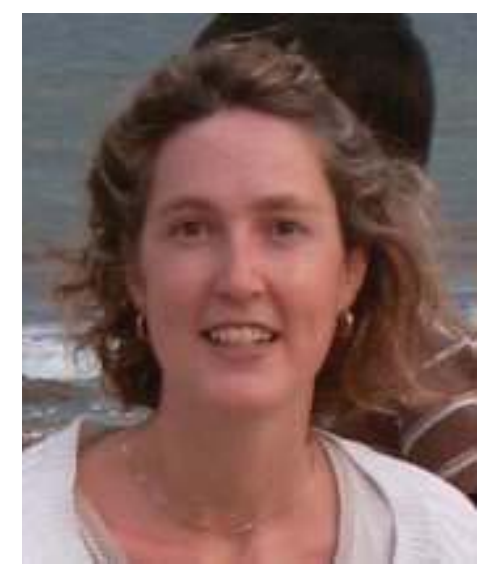

\section{AUTHOR BIOGRAPHIES}

Eva Cerezo received a Ph.D. degree in Computer Science in 2002. She is Associate Professor at the School of Engineering and Architecture and Head of the Computer Sciences and Systems Engineering Department at the University of Zaragoza. She leads the AffectiveLab, a research group that focuses on affective multimodal human computer interaction, tangible tabletops and virtual humans. She is author of more than 80 international publications. She is a member of the Executive Board of the ACM SIGCHI Spanish Local Chapter.

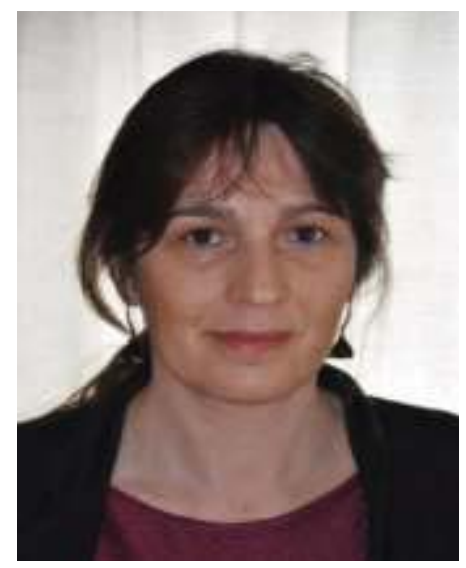

Teresa Coma received a Ph.D. degree in Psychology and Learning in 2016 from the University of Zaragoza. She is a Part-time Professor at the Psychology and Sociology Department, Education Faculty, University of Zaragoza, and a member of the AffectiveLab. She has a Degree in Social Pedagogy (UAB) and Diplomas in Special Education Teaching. She also has a Master in Psychological Intervention with $\mathrm{DBM}{ }^{\circledR}$ (Developmental Behavioral Modeling) and her lines of research are orientation in learning processes, empathy, participation and teamwork, communication, performance management and inclusion.

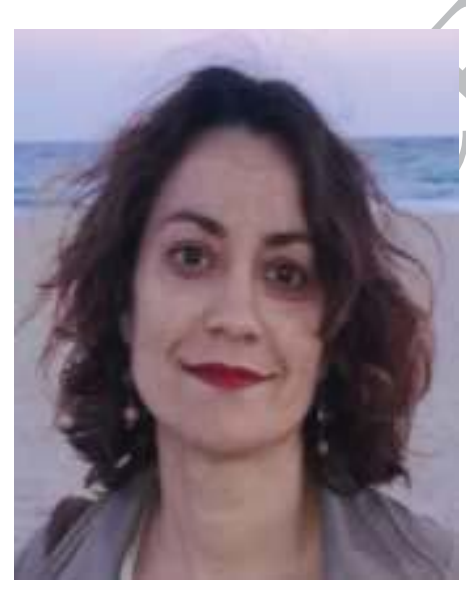

Ana Cristina Blasco-Serrano received a Ph.D. degree in Education from the University of Zaragoza (Spain) in 2017. She is a Part-time Professor at the University of Zaragoza and a member of the Ethnography research group. Her research areas are technologies for learning, educational guidance and education for citizenship. She is a member of the Chair of Development Cooperation of the University of Zaragoza. 


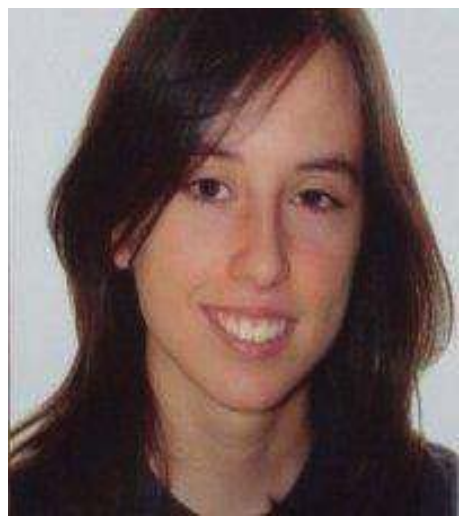

Clara Bonillo is a Ph.D. student in the Doctoral Program in Systems Engineering and Informatics, University of Zaragoza (Spain), in the AffectiveLab Group. Her research area is Tangible Interaction. In 2015, her final project entitled "Development of a tool for the design and running of activities for the elderly with the NIKVision tabletop" received the prize of the best Final Project from the Spanish Human Computer Interaction Association of which she is a member.

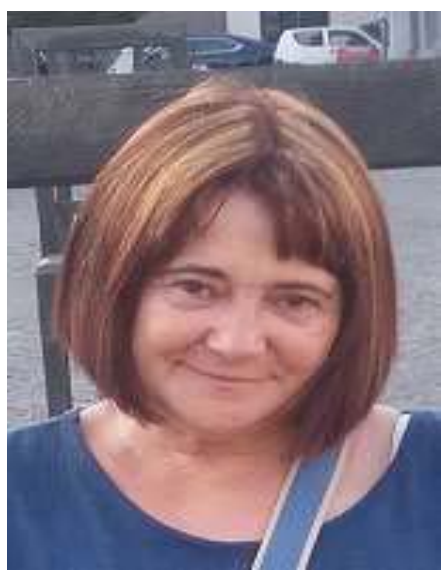

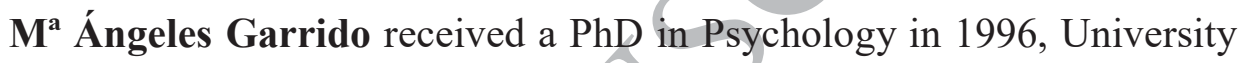
of Zaragoza. She is an Associate Professor at the Psychology and Sociology Department, Education Faculty, University of Zaragoza. She is a member of the "Educaviva: Education and psychological processes" research group. Her research areas are the teaching-learning process (especially reading processes), different models of information processing, psychological processes and curricular areas.

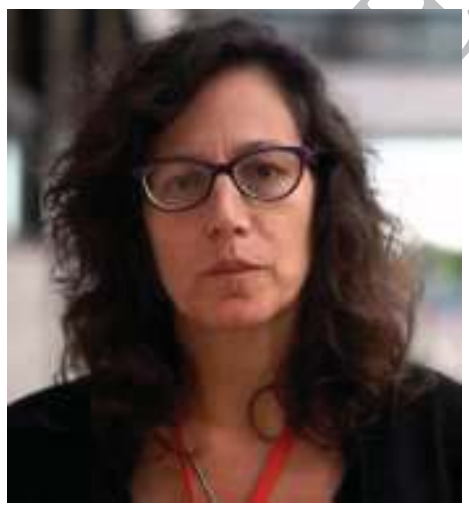

Sandra Baldassarri received a B.Sc. in Computer Science from the University of Buenos Aires, Argentina, in 1992 and a Ph.D. in Computer Science Engineering from the University of Zaragoza, Spain, in 2004. She is Assistant Professor at the University of Zaragoza (Spain) and founder member of the AffectiveLab at the University of Zaragoza. Her research interests include virtual humans, affective computing, multimodal interfaces and tangible and natural interaction. 